\title{
McMaster Mesonet soil moisture dataset: description and spatio-temporal variability analysis
}

\author{
K. C. Kornelsen ${ }^{1}$ and P. Coulibaly ${ }^{1,2}$ \\ ${ }^{1}$ School of Geography and Earth Science, McMaster University, Hamilton, Canada \\ ${ }^{2}$ Department of Civil Engineering, McMaster University, Hamilton, Canada \\ Correspondence to: P. Coulibaly (couliba@mcmaster.ca) \\ Received: 16 November 2012 - Published in Hydrol. Earth Syst. Sci. Discuss.: 19 December 2012 \\ Revised: 20 March 2013 - Accepted: 3 April 2013 - Published: 29 April 2013
}

\begin{abstract}
This paper introduces and describes the hourly, high-resolution soil moisture dataset continuously recorded by the McMaster Mesonet located in the Hamilton-Halton Watershed in Southern Ontario, Canada. The McMaster Mesonet consists of a network of time domain reflectometer (TDR) probes collecting hourly soil moisture data at six depths between $10 \mathrm{~cm}$ and $100 \mathrm{~cm}$ at nine locations per site, spread across four sites in the $1250 \mathrm{~km}^{2}$ watershed. The sites for the soil moisture arrays are designed to further improve understanding of soil moisture dynamics in a seasonal climate and to capture soil moisture transitions in areas that have different topography, soil and land cover. The McMaster Mesonet soil moisture constitutes a unique database in Canada because of its high spatio-temporal resolution. In order to provide some insight into the dominant processes at the McMaster Mesonet sites, a spatio-temporal and temporal stability analysis were conducted to identify spatio-temporal patterns in the data and to suggest some physical interpretation of soil moisture variability. It was found that the seasonal climate of the Great Lakes Basin causes a transition in soil moisture patterns at seasonal timescales. During winter and early spring months, and at the meadow sites, soil moisture distribution is governed by topographic redistribution, whereas following efflorescence in the spring and summer, soil moisture spatial distribution at the forested site was also controlled by vegetation canopy. Analysis of short-term temporal stability revealed that the relative difference between sites was maintained unless there was significant rainfall ( $>20 \mathrm{~mm}$ ) or wet conditions a priori. Following a disturbance in the spatial soil moisture distribution due to wetting, the relative soil moisture pattern re-emerged in 18 to $24 \mathrm{~h}$. Access to the McMaster Mesonet data can be provided by visiting www.hydrology.mcmaster.ca/mesonet.
\end{abstract}

\section{Introduction}

The spatial and temporal variability of soil moisture both at the surface and in the root-zone is an important control in many hydrological and atmospheric fluxes. These fluxes play a critical role in water and energy balances, and have both a direct and indirect impact on water resources and local climate. Soil moisture is of great significance for scientific and operational applications such as flood prediction and forecasting (Komma et al., 2008; Mahanama et al., 2008; Brocca et al., 2009), numerical weather prediction (Mohr et al., 2003; Loew et al., 2009; Alavi et al., 2010), climate modelling (Merlin et al., 2006; Seneviratne et al., 2010) and other disciplines, because it controls the partition of both mass and energy in hydro-meteorological processes. The potential of soil moisture data is being realized through recent technological advances, which have allowed for detailed in situ and remote soil moisture monitoring. As monitoring programs become more widespread and temporally consistent, they are providing a better understanding of the processes which determine the spatial and temporal distribution of soil moisture. The spatial distribution of soil moisture is determined by an organized structure that is perturbed by stochastic forcing (Bronstert and Bardossy, 1999), and analyses of soil moisture monitoring programs have revealed that the relative dominance of any organized or stochastic factor varies with basin, soil, topography, vegetation, meteorological and scale characteristics (Vanderlinden et al., 2012). However, no high resolution, in terms of spacing and periodicity, soil moisture data was available in Canada to carry out such analyses. The McMaster Mesonet was established to fill that gap, and to allow for insight into the factors controlling 
soil moisture distribution. An area that requires further research (Vanderlinden et al., 2012).

Blöschl and Sivapalan (1995) discussed the scale of hydrological observations as being characterized by a scaling triplet consisting of extent, spacing and support. Extent refers to the areal size represented by the observations, spacing to the distance between observation points and support the area that is represented by each observation. They similarly dissected the spatial (temporal) scale of hydrological processes into spatial extent (duration), space (time) period and integral scale (correlation length) (Blöschl and Sivapalan, 1995). Over the past decade(s) many soil moisture monitoring efforts have been undertaken to characterize the spatial-temporal distribution of soil moisture and its processes at a particular scale of interest. Intensive shortterm monitoring efforts for large areas such as the Southern Great Plains (SGP) (Familglietti et al., 1999; Mohanty et al., 2000b; Martinez-Fernandez and Ceballos, 2003; Ryu and Famiglietti, 2005, 2006) and Soil Moisture Experiments (SMEX) series (Cosh et al., 2004; Bosch et al., 2006; Choi and Jacobs, 2007; Das et al., 2008) were designed to monitor soil moisture at both a large spatial extent with moderate spacing for process description, but were limited by a moderate period and short duration. Large-scale monitoring whether of short (SMEX, SGP) or long duration (Ceballos et al., 2005; Albergel et al., 2008; Lebel et al., 2009) for calibration/validation of radiometer-scale $(\sim 40 \mathrm{~km})$ soil moisture products, use multiple observations of wide spacing to increase the extent of soil moisture observations. While coarse resolution (large spacing/extent) soil moisture is relatively abundant and has been shown to enhance hydrological and atmospheric modelling, the advantage of high resolution datasets is increasingly recognized (Wood et al., 2011) and the importance of small-scale heterogeneity has been demonstrated (Merlin et al., 2006; Alavi et al., 2010; Minet et al., 2011). Efforts to characterize soil moisture data at high spatial resolution (hillslope scale) can be described as having a moderate period (daily) and duration (days-months) (Famiglietti et al., 1998; Mohanty et al., 2000a; Hupet and Vanclooster, 2002) or are sampled at low to moderate periodicity (Grayson and Western, 1998; Wilson et al., 2003; Western et al., 2004; Brocca et al., 2010). To monitor hydrological processes, soil moisture has also been monitored at very short periods (minutes) for short durations (hours) (Torres et al., 1998). The McMaster Mesonet was designed to provide appropriate soil moisture information needed for process understanding and modelling, and developing soil moisture retrieval and extension algorithms by monitoring soil moisture with both a short (hourly) period and long duration (years) at a small extent and spacing.

With respect to spatial soil moisture distribution, some studies have found that soil moisture variability increases in wet conditions (Famiglietti et al., 1998; Vivoni et al., 2008), while others have found variability increases in dry conditions (Jacobs et al., 2004; Bosch et al., 2006; Choi and
Jacobs, 2007; Brocca et al., 2010). Analysing the results from many studies Brocca et al. (2007) found that in humid climates, spatial variability is greater when conditions are dry, whereas semi-arid environments have the highest variability in wet conditions. These relationships are also subject to considerations of scale and topography. For example, scale is important as homogenous rainfall tends to decrease soil moisture variability and heterogeneous rainfall increases it (Cosh et al., 2004), whereas Famiglietti et al. (1998) found that following a rainstorm upper portions of a hillslope were more variable than lower portions of the hillslope, causing an overall increase in variability when the entire landscape was considered. At smaller extents, precipitation is generally homogenous and the redistribution of soil moisture by topography, soil texture and vegetation become important post-precipitation (Wilson et al., 2003; Famiglietti et al., 2008). During wetting, soil moisture variability is dominated by the soils' infiltration capacity and topographic redistribution (Famiglietti et al., 1998; Western and Blöschl, 1999; Western et al., 2004; Vivoni et al., 2008; Heathman et al., 2009), while under dry conditions variability is maintained by the soil water holding capacity and concavity of the surface (Famiglietti et al., 1998; Peters-Lidard et al., 2001; Vivoni et al., 2008). Vegetation is also a potentially important predictor of soil moisture distribution that can redistribute soil moisture affording a homogenizing effect (Ivanov et al., 2010) or partially explain soil moisture spatial variability in some landscapes (Hupet and Vanclooster, 2002; Bosch et al., 2006), whereas others have found that the role of vegetation in soil moisture distribution is only minor (Cosh et al., 2004). Vachaud et al. (1985) noticed that the relative rank of soil moisture at a particular location with respect to similar nearby locations was persistent in time, leading to the assertion of temporal stability, or more appropriately rank stability (Chen, 2006). The presence of temporally stable soil moisture patterns has been noted during several soil moisture campaigns (Martinez-Fernandez and Ceballos, 2003; Cosh et al., 2004; Bosch et al., 2006; Vivoni et al., 2008) and has also been found to result from soil, topographic and vegetation influences (Vivoni et al., 2008). However, flat topography and soil moisture redistribution have also been observed to result in poor temporal stability (Mohanty et al., 2000b; Mohanty and Skaggs, 2001). None of those soil moisture dynamics analysis studies were conducted in Canada because of the lack of appropriate soil moisture data. The role of seasonal effects on soil moisture variability and stability in cool and snowy climates remains an open research area. The McMaster Mesonet database will help to fill that gap as well.

This paper introduces and describes the long-term, high-resolution McMaster Mesonet dataset located in the $1250 \mathrm{~km}^{2}$ Hamilton-Halton Watershed in Southern Ontario, Canada. It also provides a spatio-temporal analysis of the hourly soil moisture data collected at four sites since autumn 2006. The experiment was designed specifically for application to high-resolution remote sensing soil moisture 
validation, hydrological data assimilation, and process understanding. The unique aspect of this dataset is the multiple soil moisture profiles that are collected at each site for both an hourly period and long duration. This will allow for the characterization of hillslope-scale soil moisture variability at event, seasonal and inter-annual temporal scales, and will provide insight into the influence of topography, vegetation and atmospheric conditions on small-scale soil moisture dynamics. Also, most soil moisture experiments described in the literature are from the USA, Europe and Australia and so, to the best knowledge of the authors, this paper represents the first attempt to describe long-term soil moisture dynamics in Canada and specifically the Great Lakes region. It is expected that the McMaster Mesonet will monitor hillslope-scale processes that are representative of those occurring in the southern Great Lakes region of Canada in general and the Hamilton-Halton watershed in particular. Due to the limited spatial extent of the monitoring sites, it is surmised that the dataset is better representative of regional temporal trends than regional spatial soil moisture. The main dataset consists of a series of four high-resolution soil moisture arrays collecting hourly distributed soil moisture profile information since 2006 with an expected lifespan of fifteen years. The soil moisture data is supplemented by six weather stations and nine rain gauges distributed throughout the watershed. This dataset can be made available to the broader research community by visiting the website www.hydrology.mcmaster.ca/mesonet and plans are underway to include the dataset in the International Soil Moisture Network (Dorigo et al., 2011). This paper would serve as an essential reference for the McMaster Mesonet data users.

\section{McMaster mesonet}

\subsection{Hamilton-Halton Watershed}

The Hamilton-Halton Watershed (Fig. 1) is part of the Lake Ontario drainage basin in Ontario, Canada, and has approximately $980 \mathrm{~km}^{2}$ rural agricultural/forested land and $270 \mathrm{~km}^{2}$ of urbanized/industrial land. The urbanized land in the watershed is concentrated within a band that extends approximately $7.5 \mathrm{~km}$ from the Lake Ontario shoreline, with the notable exception of the Town of Milton which covers an area of $25 \mathrm{~km}^{2}$, in the northern-central part of the watershed. The major geographic features include the Lake Iroquois Plains, which are an ancient glacial extension of the current Lake Ontario shoreline and the Niagara Escarpment. The area surrounding the Niagara Escarpment is primarily mixed deciduous/coniferous woodland, and agriculture dominates the remainder of the rural area. The primary crops are maize, soy and grains with some tender fruit crops. The watershed is subdivided into six primary subwatersheds, Sixteen Mile Creek, Bronte Creek, North Shore, Grindstone Creek, Spencer Creek and Red Hill Creek, each with their

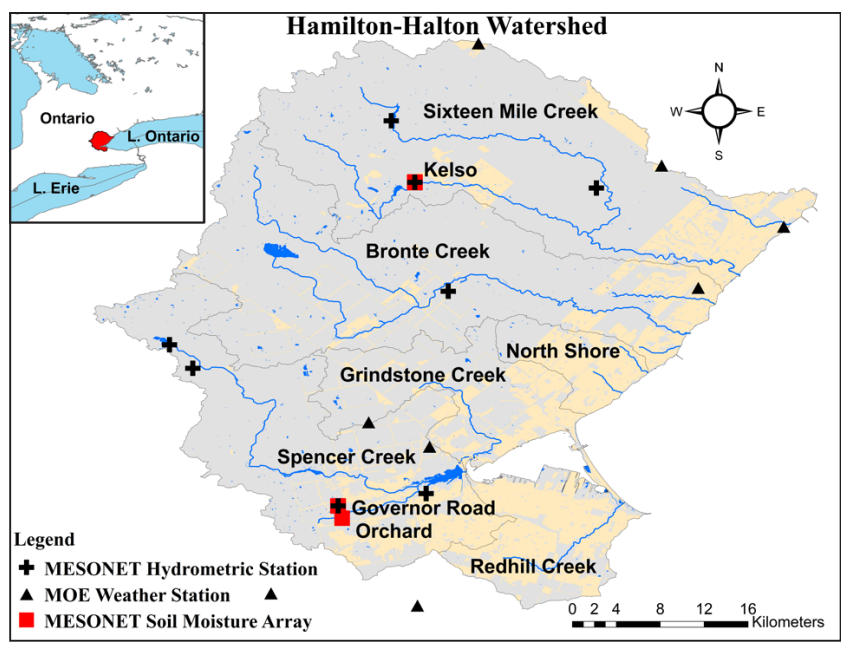

Fig. 1. Location map of the Hamilton-Halton Watershed including subwatersheds and the locations of the soil moisture arrays and hydro-meteorological stations.

own network of tributaries. Sixteen Mile Creek is the northernmost subwatershed and covers an area of $357 \mathrm{~km}^{2}$ and is predominantly agricultural. The Bronte Creek Watershed encompasses an area of $304 \mathrm{~km}^{2}$ and has the largest proportion of forested area around the Niagara Escarpment. Grindstone Creek has a catchment area of $99 \mathrm{~km}^{2}$ and is largely rural agricultural with forest and some urban area in the south-east. Both North Shore Creek $\left(44 \mathrm{~km}^{2}\right)$ and Red Hill Creek $\left(93 \mathrm{~km}^{2}\right)$ are predominantly urban areas and have been modified to accommodate urban storm-water management. Spencer Creek encompasses an area of $260 \mathrm{~km}^{2}$ and is predominantly rural/agricultural and includes part of the City of Hamilton and forested area around the Niagara Escarpment in the south-eastern portion of the subwatershed. It is important to note that areas reported herein are consistent with what is portrayed in Fig. 1, however, in reality the subwatersheds as reported also contain small waterways which drain directly into Lake Ontario but are not distinguished herein.

The climate of the watershed can be classified as humid continental with average annual precipitation of $910 \mathrm{~mm}$ distributed evenly throughout the year. The watershed experiences four distinct seasons, with average summer temperatures of $21^{\circ} \mathrm{C}$ and average winter temperatures of $-6^{\circ} \mathrm{C}$ (1971-2000 Canadian Climate Normals). A time series plot of climate variables and average soil moisture data from the McMaster Mesonet for 2006-2012 can be seen in Fig. 2 and a climate summary can be found in Table 2 . The monthly and annual climate patterns at the Britannia weather station, located in the centre of the watershed, and the long-term climate normals for the Hamilton airport $(5 \mathrm{~km}$ south of watershed) are presented for comparison. It should be noted that the Mesonet precipitation presented in Table 2 represents primarily rainfall as there is no active collection of data for snow water equivalent. The climate in the watershed is 


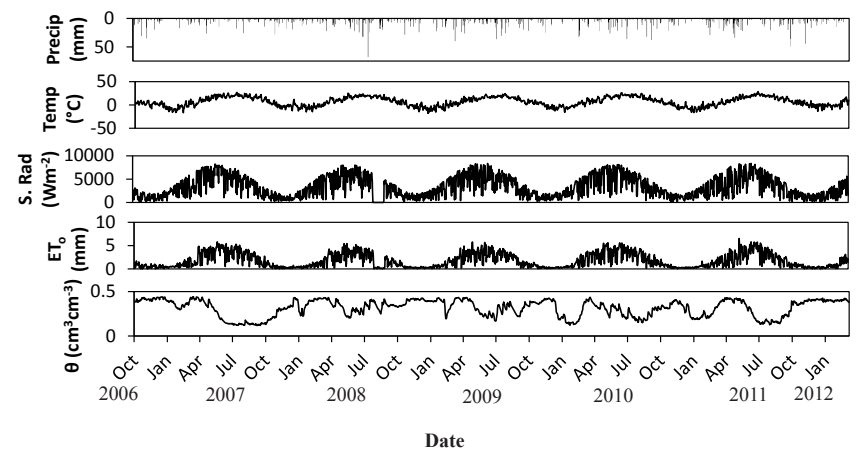

Fig. 2. Daily time series plot of $10 \mathrm{~cm}$ site averaged soil moisture from $\mathrm{K} 1$ and daily time series of meteorological data collected at Kelso.

similar to the climate normals, with the exception of 2007, which had considerably lower than normal summer precipitation. Consequently, a prolonged period of low soil moisture can be seen throughout the summer of 2007 in Fig. 2, which is nearly two standard deviations below the mean soil moisture for the study period. A similar dry spell occurred during the summer of 2011, but was compensated for annually by a wetter-than-normal spring and autumn in that same year. The climatic variability in the watershed during the course of study is ideal for studying soil moisture variability as a large variety of conditions have been observed within a relatively short period of study, by climatological standards.

\subsection{Data description}

A soil moisture "site" refers to the location of an entire soil moisture array, i.e. Kelso 1 (K1), Kelso 2 (K2), Governor Road (GR) or Orchard (OR). Each site contains nine stations which are numbered from 1 to 9 , where a "station" refers to a vertical soil moisture profile at a particular geographic location (Figs. 3, 4). A station has six associated measurements for each sampling period for the six depths indicated in Table 2. Soil moisture characterized as "daily" refers to the mean value, and its variance, of a discrete $24 \mathrm{~h}$ period measured using Eastern Standard Time.

The McMaster Mesonet provides long-term hourly soil moisture data at four sites, Kelso 1, Kelso 2 , Governor Road and Orchard, which have been collecting data continuously since 2006. Each site contains 54 Campbell Scientific CS616 multiplexed time domain reflectometry (TDR) probes attached to a CR10X data logger through nine soil moisture profile stations with six TDR probes each. Each profile station collects measurements at six depths between 10 to $100 \mathrm{~cm}$, with specific depths given in Table 2. At each of the four sites, the nine profile stations are distributed in a grid pattern, where a $100 \mathrm{~cm}$ pit was dug at each station and six TDR probes were inserted horizontally into the soil. The majority of probes were inserted at 10, 20, 30, 50, 70 and $100 \mathrm{~cm}$ depths in order to capture the change in soil

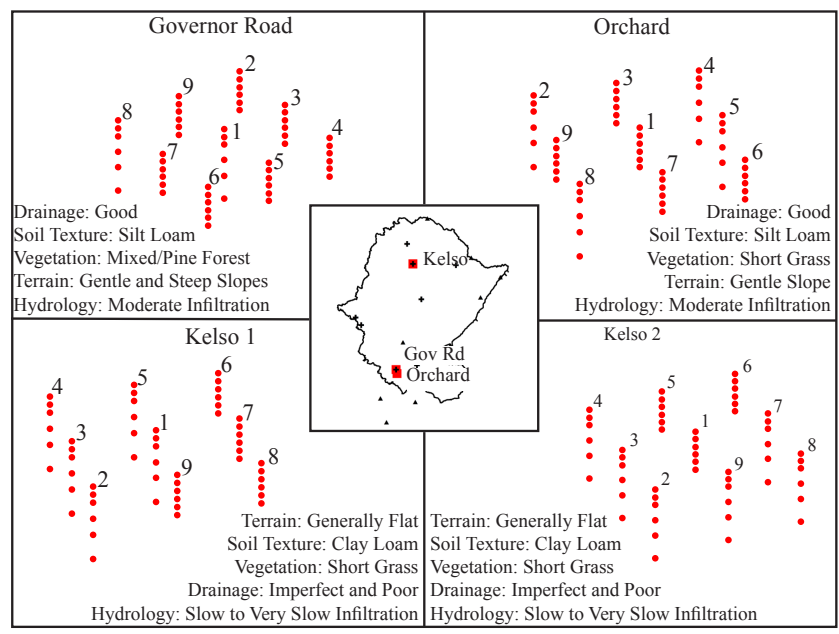

Fig. 3. Three dimensional schematic representation of the McMaster Mesonet. Note: the vertical dimensions are to scale, whereas spatial dimensions are not (see Fig. 4). The symbols in the centre map are consistent with Fig. 1.

moisture in the hydrologically dynamic layer. In some instances, high clay content and topographic conditions did not allow for the full $100 \mathrm{~cm}$ depth to be reached and the TDR probes were inserted at 10,20,30,40,50 and $60 \mathrm{~cm}$ depths instead (see Table 2). All of the TDR profiles are connected to a data logger at the centre of the array at station 1. Each TDR array has an associated tipping bucket rain gauge and automated weather stations are associated with the TDR arrays located between $\mathrm{K} 1$ and $\mathrm{K} 2$ and at GR. The soil moisture data has been preprocessed to remove most erroneous measurements and when less than 72 temporally consecutive missing values were present, the data was infilled using linear interpolation (Kornelsen and Coulibaly, 2013) and/or the soil layer relative difference method if some values were missing between stations (Kornelsen and Coulibaly, 2013; Dumedah and Coulibaly, 2011). In addition to the Campbell Scientific datasets, a Stevens Water Hydra Probe array is operated in conjunction with the CS616 array at Kelso 1 providing an independent soil moisture dataset for comparison/validation, where Hydra Probes are co-located at each station and collect soil moisture information at depths of 5, 10, 20, 30, 40 and $50 \mathrm{~cm}$ at half-hourly intervals.

The sites were selected to represent three distinct landscapes common to the watershed and are located on protected conservation land to ensure the safety and longevity of the monitoring network. The spatial extent to which the soil moisture arrays are representative is considered limited as hillslope-scale soil moisture processes, rather than watershed-scale dynamics, are emphasized by the distribution of TDR probes. However, because the sites are located in landscapes representative of those in the watershed, it is hoped that future studies can ascertain the support of the dataset and potentially extend the representativeness to the 
Table 1. Climatic conditions based on Britannia weather station (located at the centre of the watershed) and the Hamilton airport weather station (approx. $5 \mathrm{~km}$ south of watershed).

\begin{tabular}{|c|c|c|c|c|c|c|c|c|c|c|c|c|c|}
\hline & Jan & $\mathrm{Feb}$ & Mar & Apr & May & Jun & Jul & Aug & Sep & Oct & Nov & Dec & Ann \\
\hline \multicolumn{14}{|c|}{ Hamilton airport (1971-2000) } \\
\hline Daily Max Temp $\left({ }^{\circ} \mathrm{C}\right)$ & -2.2 & -1.2 & 4.0 & 11.2 & 18.5 & 23.7 & 26.3 & 25.1 & 20.7 & 13.8 & 7.0 & 0.9 & 12.3 \\
\hline Daily Min Temp $\left({ }^{\circ} \mathrm{C}\right)$ & -9.7 & -9.1 & -4.5 & 1.2 & 7.3 & 12.4 & 15.1 & 14.5 & 10.2 & 4.4 & -0.4 & -6.2 & 2.9 \\
\hline Daily Mean Temp $\left({ }^{\circ} \mathrm{C}\right)$ & -6 & -5.2 & -0.3 & 6.3 & 12.9 & 18.0 & 20.8 & 19.8 & 15.5 & 9.1 & 3.3 & -2.7 & 7.6 \\
\hline Rainfall (mm) & 29.5 & 25.7 & 48.6 & 69.6 & 75.0 & 83.9 & 86.5 & 80.6 & 82.1 & 71.6 & 68.1 & 43.7 & 764.8 \\
\hline Precipitation (mm) & 65.8 & 55.3 & 74.8 & 78.0 & 75.6 & 83.9 & 86.5 & 80.6 & 82.1 & 72.5 & 78.6 & 76.6 & 910.1 \\
\hline \multicolumn{14}{|c|}{ Mesonet - Britannia (2007) } \\
\hline Daily Max Temp $\left({ }^{\circ} \mathrm{C}\right)$ & -0.3 & -4.9 & 4.2 & 9.2 & 20.3 & 26.0 & 26.1 & 26.5 & 23.4 & 17.8 & 5.5 & -0.4 & 12.8 \\
\hline Daily Min Temp $\left({ }^{\circ} \mathrm{C}\right)$ & -7.4 & -13.1 & -4.6 & 1.4 & 7.6 & 13.4 & 13.7 & 15.1 & 10.9 & 8.2 & -1.9 & -6.3 & 3.1 \\
\hline Daily Mean Temp $\left({ }^{\circ} \mathrm{C}\right)$ & -3.8 & -9.0 & -0.2 & 5.3 & 14.0 & 19.7 & 19.9 & 20.8 & 17.2 & 13.0 & 1.8 & -3.3 & 7.9 \\
\hline Precipitation (mm) & 51.8 & 10.6 & 57.8 & 70.8 & 46.0 & 43.4 & 16.8 & 28.0 & 25.6 & 50.4 & 66.6 & 62.0 & 529.8 \\
\hline \multicolumn{14}{|c|}{ Mesonet - Britannia (2008) } \\
\hline Daily Max Temp $\left({ }^{\circ} \mathrm{C}\right)$ & 0.5 & -1.3 & 2.0 & 14.0 & 16.3 & 23.7 & 26.1 & 22.3 & 21.1 & 13.4 & 5.7 & 0.0 & 12.0 \\
\hline Daily Min Temp $\left({ }^{\circ} \mathrm{C}\right)$ & -6.4 & -9.9 & -6.4 & 2.7 & 5.3 & 13.6 & 15.2 & 7.3 & 10.7 & 3.2 & -1.4 & -8.2 & 2.2 \\
\hline Daily Mean Temp $\left({ }^{\circ} \mathrm{C}\right)$ & -2.9 & -5.6 & -2.2 & 8.3 & 10.8 & 18.7 & 20.7 & 14.8 & 15.9 & 8.3 & 2.2 & -4.1 & 7.1 \\
\hline Precipitation $(\mathrm{mm})$ & 58.0 & 64.6 & 49.0 & 50.0 & 53.8 & 108.6 & 143.2 & 120.0 & 102.2 & 36.6 & 77.2 & 100.6 & 963.8 \\
\hline \multicolumn{14}{|c|}{ Mesonet - Britannia (2009) } \\
\hline Daily Max Temp $\left({ }^{\circ} \mathrm{C}\right)$ & -5.2 & 0.8 & 5.0 & 11.8 & 18.1 & 21.9 & 23.1 & 25.1 & 21.1 & 11.6 & 9.1 & -0.2 & 11.9 \\
\hline Daily Min Temp $\left({ }^{\circ} \mathrm{C}\right)$ & -13.5 & -8.8 & -4.5 & 1.8 & 6.5 & 11.4 & 13.2 & 14.7 & 10.5 & 3.7 & 1.0 & -6.3 & 2.5 \\
\hline Daily Mean Temp $\left({ }^{\circ} \mathrm{C}\right)$ & -9.4 & -4.0 & 0.3 & 6.8 & 12.3 & 16.7 & 18.2 & 19.9 & 15.8 & 7.7 & 5.0 & -3.3 & 7.2 \\
\hline Precipitation $(\mathrm{mm})$ & 17.8 & 71.2 & 63.0 & 137.6 & 50.0 & 52.8 & 97.4 & 120.8 & 31.4 & 82.9 & 32.5 & 91.6 & 849.0 \\
\hline \multicolumn{14}{|c|}{ Mesonet - Britannia (2010) } \\
\hline Daily Max Temp $\left({ }^{\circ} \mathrm{C}\right)$ & -2.6 & -0.9 & 8.2 & 15.9 & 20.4 & 23.1 & 28.0 & 26.5 & 20.3 & 14.1 & 7.7 & -1.8 & 13.3 \\
\hline Daily Min Temp $\left({ }^{\circ} \mathrm{C}\right)$ & -8.8 & -7.4 & -1.1 & 3.8 & 8.9 & 13.6 & 16.4 & 15.7 & 10.2 & 4.6 & -1.1 & -7.2 & 4.0 \\
\hline Daily Mean Temp $\left({ }^{\circ} \mathrm{C}\right)$ & -5.7 & -4.1 & 3.6 & 9.8 & 14.7 & 18.4 & 22.2 & 21.1 & 15.2 & 9.4 & 3.3 & -4.5 & 8.6 \\
\hline Precipitation $(\mathrm{mm})$ & 20.1 & 19.0 & 91.2 & 48.6 & 55.2 & 138.6 & 127.0 & 39.4 & 106.8 & 73.0 & 129.0 & 31.3 & 897.2 \\
\hline \multicolumn{14}{|c|}{ Mesonet - Britannia (2011) } \\
\hline Daily Max Temp $\left({ }^{\circ} \mathrm{C}\right)$ & -3.8 & -1.2 & 3.0 & 10.6 & 17.7 & 23.3 & 29.6 & 26.5 & 21.7 & 14.5 & 10.3 & 3.5 & 13.0 \\
\hline Daily Min Temp $\left({ }^{\circ} \mathrm{C}\right)$ & -11.9 & -10.2 & -5.8 & 1.2 & 8.4 & 12.5 & 16.7 & 15.0 & 11.3 & 5.5 & 2.0 & -3.6 & 3.4 \\
\hline Daily Mean Temp $\left({ }^{\circ} \mathrm{C}\right)$ & -7.8 & -5.7 & -1.4 & 5.9 & 13.0 & 17.9 & 23.1 & 20.8 & 16.5 & 10.0 & 6.2 & 0.0 & 8.2 \\
\hline Precipitation $(\mathrm{mm})$ & 24.4 & 34.2 & 87.0 & 100.6 & 142.2 & 54.0 & 12.0 & 86.4 & 74.2 & 125.2 & 82.6 & 68.0 & 890.8 \\
\hline \multicolumn{14}{|c|}{ Mesonet - Britannia (2007-2011) } \\
\hline Daily Max Temp $\left({ }^{\circ} \mathrm{C}\right)$ & -2.3 & -1.5 & 4.5 & 12.3 & 18.6 & 23.6 & 26.6 & 25.4 & 21.5 & 14.3 & 7.7 & 0.2 & 12.6 \\
\hline Daily Min Temp $\left({ }^{\circ} \mathrm{C}\right)$ & -9.6 & -9.9 & -4.5 & 2.2 & 7.3 & 12.9 & 15.0 & 13.6 & 10.7 & 5.0 & -0.3 & -6.3 & 3.0 \\
\hline Daily Mean Temp $\left({ }^{\circ} \mathrm{C}\right)$ & -5.9 & -5.7 & 0.0 & 7.2 & 13.0 & 18.3 & 20.8 & 19.5 & 16.1 & 9.7 & 3.7 & -3.0 & 7.8 \\
\hline Precipitation (mm) & 34.4 & 39.9 & 69.6 & 81.5 & 69.4 & 79.5 & 79.3 & 78.9 & 68.0 & 73.6 & 77.6 & 70.7 & 826.1 \\
\hline
\end{tabular}

two subwatersheds in which the arrays are located. The distribution of the additional hydro-meteorological stations of the McMaster Mesonet provides a relatively dense monitoring network for watershed-scale applications, which can be supported by the hillslope-scale soil moisture arrays.

The Kelso sites (K1 \& K2) are located in the northern portion of the watershed in an area that is predominantly agricultural land. The soil is a grey-brown Podzol (clay loam) that is a poorly drained with a higher clay content at depth $(80-100 \mathrm{~cm})$. The A horizon is light grey and mottled near the Bt horizon. These soils seat atop calcareous till at a depth of approximately $75 \mathrm{~cm}$ (Gillespie et al., 1971). The terrain is generally flat with some hummocks and a few small gentle sloping hills at the edge of the site. The land-cover is predominantly meadow with some recently planted coniferous and aspen trees scattered throughout the site. The K1 and $\mathrm{K} 2$ sites are located adjacent to each other to allow sampling of a larger area. However, both datasets are collected and stored independently and will herein often be considered as distinct data, in spite of their co-location, for the purposes of describing the dataset.

The GR and OR sites are located in the Dundas Valley Conservation Area. The Dundas Valley is part of the Niagara Escarpment and is predominantly covered by mixed Carolinian forests, and fields. Both sites have Ancaster series grey-brown Podzolic soils with good drainage and moderate infiltration. Typical Ancaster soils have a thin Ap horizon of greyish-brown silt loam over a thicker Ae brown silt loam. 
Table 2. McMaster Mesonet site and station description.

\begin{tabular}{|c|c|c|c|}
\hline Site Name \& Description & Station & Probe Depths (cm) & Station Description \\
\hline Orchard - Dundas Valley & 1 & $10,20,30,40,50,60$ & clear sky, side slope \\
\hline Soil Texture: silt loam & 2 & $10,20,30,50,70,100$ & partial canopy cover, downslope \\
\hline Vegetation: short grass & 3 & $10,20,30,40,50,60$ & clear sky, downslope \\
\hline Terrain: gentle slopes, hill-slope & 4 & $10,20,30,50,70,100$ & clear sky, downslope \\
\hline Drainage: soil drains well & 5 & $10,20,30,50,70,100$ & clear sky, side slope \\
\hline \multirow[t]{4}{*}{ Hydrology: moderate infiltration when wet } & 6 & $10,20,30,40,50,60$ & Partial canopy cover, upslope \\
\hline & 7 & $10,20,30,40,50,60$ & clear sky, upslope \\
\hline & 8 & $10,20,30,50,70,100$ & under tree canopy, upslope \\
\hline & 9 & $10,20,30,40,50,60$ & clear sky, side slope \\
\hline Governor Road - Dundas Valley & 1 & $10,20,30,50,70,100$ & clear sky, close to tree, mid-elevation \\
\hline Soil Texture: silt loam & 2 & $10,20,30,40,50,60$ & canopy cover, mixed forest, side sloping \\
\hline Vegetation: mixed forest; generally pine & 3 & $10,20,30,40,50,60$ & partial canopy cover, in valley \\
\hline Terrain: gentle and steep slopes & 4 & $10,20,30,40,50,60$ & clear sky, close to tree, uphill \\
\hline Drainage: soil drains well & 5 & $10,20,30,40,50,60$ & dense canopy cover, mid-elevation \\
\hline \multirow[t]{4}{*}{ Hydrology: moderate infiltration when wet } & 6 & $10,20,30,40,50,60$ & partial canopy cover, downhill \\
\hline & 7 & $10,20,30,40,50,60$ & clear sky, uphill, upslope \\
\hline & 8 & $10,20,30,50,70,100$ & canopy cover, mixed forest, upslope valley \\
\hline & 9 & $10,20,30,40,50,60$ & canopy cover, mixed forest, side valley \\
\hline Kelso 1 & 1 & $10,20,30,50,70,100$ & clear sky, tall grass, mid-elevation \\
\hline Soil Texture: clay loam & 2 & $10,20,30,50,70,100$ & clear sky, tall grass, low elevation \\
\hline Vegetation: short grass (light vegetation) & 3 & $10,20,30,50,70,100$ & clear sky, tall grass, high elevation \\
\hline Terrain: generally flat & 4 & $10,20,30,50,70,100$ & clear sky, tall grass, high elevation \\
\hline Drainage: is imperfect and poor & 5 & $10,20,30,50,70,100$ & clear sky, short grass, mid-elevation \\
\hline \multirow[t]{4}{*}{ Hydrology: slow to very slow infiltration when wet } & 6 & $10,20,30,40,50,60$ & clear sky, short grass, mid-elevation \\
\hline & 7 & $10,20,30,40,50,60$ & clear sky, short grass, low elevation \\
\hline & 8 & $10,20,30,40,50,60$ & clear sky, short grass, mid-elevation \\
\hline & 9 & $10,20,30,40,50,60$ & Clear sky, tall grass, high elevation \\
\hline Kelso 2 & 1 & $10,20,30,40,50,60$ & clear sky, short grass, low elevation \\
\hline Soil Texture: clay loam & 2 & $10,20,30,50,70,100$ & clear sky, tall grass, high elevation \\
\hline Vegetation: short grass (light-to-dense vegetation) & 3 & $10,20,30,50,70,100$ & clear sky, tall grass, high elevation \\
\hline Terrain: generally flat & 4 & $10,20,30,50,70,100$ & clear sky, tall grass, mid-elevation \\
\hline Drainage: is imperfect and poor & 5 & $10,20,30,40,50,60$ & clear sky, short grass, mid-elevation \\
\hline \multirow[t]{4}{*}{ Hydrology: slow to very slow infiltration when wet } & 6 & $10,20,30,40,50,60$ & clear sky, dense grass, low elevation \\
\hline & 7 & $10,20,30,50,70,100$ & clear sky, dense grass, low elevation \\
\hline & 8 & $10,20,30,50,70,100$ & clear sky, dense grass, mid-elevation \\
\hline & 9 & $10,20,30,50,70,100$ & clear sky, dense grass, high elevation \\
\hline
\end{tabular}



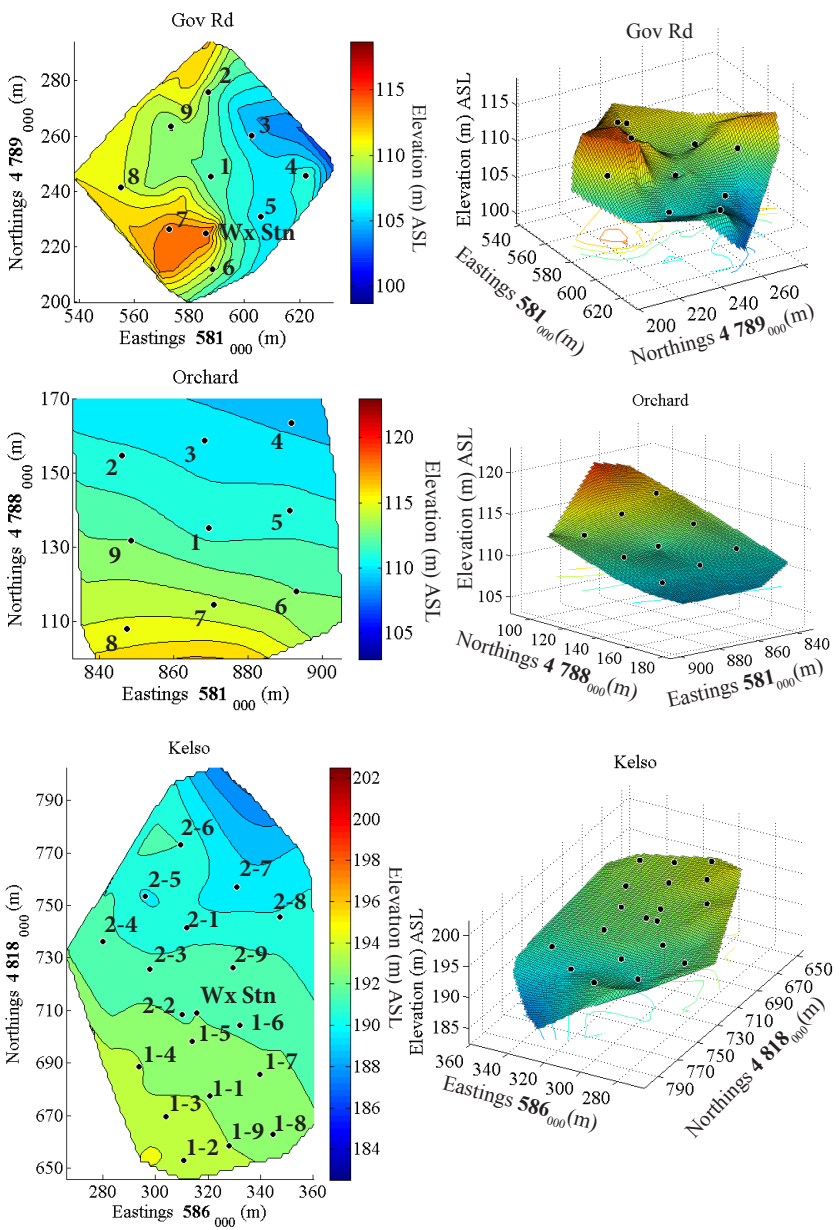

Fig. 4. Topography and layout of the soil moisture arrays at GR (top), OR (middle) and K1/K2 (bottom) as contour plots (left) and surface renderings (right). Contours were derived using natural neighbour interpolation using topographic data collected with an Ashtech MM100 GPS and have an approximate horizontal RMSE of $20 \mathrm{~cm}$ and vertical RMSE of $50 \mathrm{~cm}$. The surface plot vertical exaggeration is $3 \mathrm{X}$. Note: surface and contour plots have different orientations to enhance the visual interpretation of the surface plot.

The B horizons are well developed and contain clay and iron accumulations. The $\mathrm{C}$ horizon typically begins at $75 \mathrm{~cm}$ depth and has a higher clay content (Presant et al., 1965). OR is located in a reclaimed apple orchard that is covered by meadow vegetation and has sparse apple trees. The site covers the transition between a gentle north facing slope and a flat plateau. The GR site is located on mixed terrain and has steep and gentle slopes having mixed/pine forest covering most of the site with small open areas around the weather station and on the steep slopes. Figure 4 shows the terrain of each site and the locations of the soil moisture stations within each site.

The soil moisture arrays are supplemented with six weather stations and nine rain gauges distributed throughout the watershed. The weather stations are a mix of Campbell
Scientific and HOBO (data logger) stations, recording halfhourly observations of air temperature, relative humidity, vapour pressure, saturation vapour pressure, precipitation (rain only), incoming solar radiation, wind speed and wind direction. Additionally, grass reference evapotranspiration is calculated online from the collected data within the weather station using the Penman-Monteith equation (Campbell Scientific, 1999). The weather/hydrometric stations were distributed to provide good characterization of the watershed with considerations given to accessibility and security. There are also 8 weather stations within or near the watershed that are operated by the Ontario Ministry of Natural Resources or Environment Canada, and which are also shown in Fig. 1. While not continuously recorded by the McMaster Mesonet, limited snowfall and snow depth measurements in and near the watershed are available from Environment Canada weather stations. In addition to meteorological data, water level, discharge and groundwater data are available independently from Environment Canada's HYDAT (hydrometric data) database and the Ontario Ministry of the Environment.

\subsection{Campbell Scientific TDR and Stevens Hydra Probe Comparison}

At the K1 site, Stevens Hydra Probes were installed alongside the CS616 TDR probes at depths of $10-50 \mathrm{~cm}$ in $10 \mathrm{~cm}$ increments in order to provide a comparison between the two data products, Hydra Probes were additionally installed at each station at a depth of $5 \mathrm{~cm}$. Gravimetric sampling was not conducted regularly at this site in conjunction with automated measurements; therefore, only a comparison between measurements can be made, which is summarized in Fig. 5. In general, the soil moisture data from the CS TDR and Hydra Probes follow similar temporal trends at all sites in terms of the rate of wetting and drying. The positive differences in Fig. 5 indicate that the CS TDR records higher soil moisture values than the Hydra Probe, which is common amongst all depths. Overall, small differences (less than $5 \%$ on average) are observed between the two records. The smallest differences between the two datasets occur at the 30 and $50 \mathrm{~cm}$ depths, whereas larger differences are observed between 10 and $20 \mathrm{~cm}$ depths. This is mostly due to the large variability of soil moisture in the top layers compared to deeper layers. Some larger differences between the two measurements occur at stations 3 and 4 at all depths (Fig. 5). This is in part due to the specific locations of the two stations ( 3 and 4$)$. At those two locations the CS TDR measurements show higher variability compared to other sites. However, in general, the differences are mostly due to the noise in hourly data. 

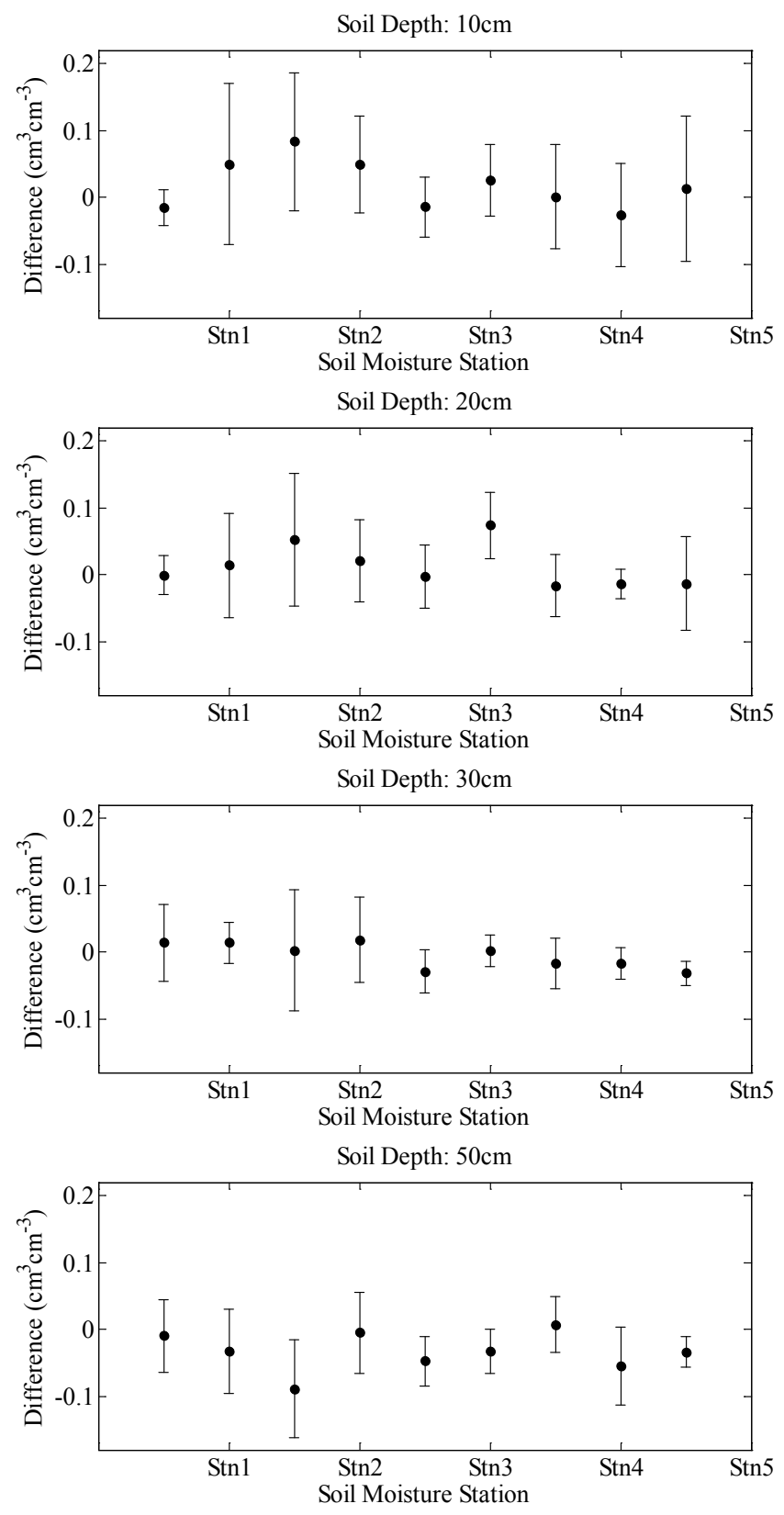

Fig. 5. Mean difference between Campbell Scientific CS616 TDR and Stevens Water Hydra Probe hourly soil moisture values at K1 from 2007 to 2011 . The error bars represent one standard deviation.

\section{Methodology}

\subsection{Statistical methods}

For both the analysis and manipulation of soil moisture data, and for ease of use/presentation the data is characterized using standard sample statistics. Herein, both spatial and temporal soil moisture statistics will be presented and so we will differentiate the statistics in terms of variability in both space and time.
Let $\theta_{i j k}$ be the soil moisture $\theta$ at station $i$ and time $k$ for the sampling depth $j$. The spatial mean soil moisture for a site $\overline{\theta_{j k}}$ can be calculated as:

$\overline{\theta_{j k}}=\frac{1}{N_{i}} \sum_{i=1}^{N i} \theta_{i j k}$,

where $N_{i}$ is the number of stations $i$ (usually 9) at which soil moisture is sampled for a given depth $j$. Similarly the daily mean soil moisture for a station $\overline{\theta_{i j}}$ is given as:

$\overline{\theta_{i j}}=\frac{1}{M} \sum_{k=1}^{M} \theta_{i j k}$,

where $M$ is the number of hours (usually 24) over which the mean value is taken. The daily soil moisture for a site at a specific depth is given by

$\overline{\theta_{j}}=\frac{1}{N_{i} M} \sum_{i=1}^{N i} \sum_{k=1}^{M} \theta_{i j k}=\frac{1}{N_{i}} \sum_{i=1}^{N i} \overline{\theta_{i j}}$,

where the mean daily soil moisture for each station is first derived and the spatial mean is then calculated. For ease of consideration, the standard deviation and variance of soil moisture is only considered based on the second summation. Therefore the daily variance of a station is given by

$\sigma_{i j}^{2}=\frac{1}{M-1} \sum_{k=1}^{M}\left(\theta_{i j k}-{\overline{\theta_{j k}}}^{2}\right.$,

whereas the variance of the daily soil moisture at the entire site for depth $j$ is given by

$\sigma_{j}^{2}=\frac{1}{N_{i}} \sum_{i=1}^{N i}\left(\theta_{i j}-\overline{\theta_{j}}\right)^{2}$,

where the temporal variance determined in Eq. (4) is ignored when calculating the daily site variance in Eq. (5). Because hourly soil moisture is highly autocorrelated, the daily temporal variability of soil moisture at each station is minimal in comparison to the spatial variability. Therefore, the loss of information resulting from the considered averaging scheme is assumed negligible. The above equations can also be extended to apply to monthly soil moisture where daily soil moisture at a site/station is first calculated and Eqs. (2)-(3) and (4)-(5) are reapplied using $M$ as days instead of hours.

\subsection{Temporal stability}

The concept of temporal stability was first proposed by Vachaud et al. (1985) and is used to determine the temporal persistence of the spatial soil moisture pattern. Analysis of the temporal persistence leads to some understanding of the processes that influence the organized portion of the spatial soil moisture pattern. Temporal stability analysis is conducted using the parametric test of the relative differences, 
where the relative difference $\delta_{i j k}$ at station $i$, depth $j$ and time $k$ is given by

$\delta_{i j k}=\frac{\theta_{i j k}-\overline{\theta_{j k}}}{\overline{\theta_{j k}}}$.

In order to mitigate the effects of stochastic influences on the soil moisture pattern and the relative difference statistic, the mean and standard deviation can be calculated where the mean relative difference $\overline{\delta_{i j}}$ and its standard deviation $\sigma\left(\delta_{i j}\right)$ are given by

$\overline{\delta_{i j}}=\frac{1}{M} \sum_{k=1}^{M} \delta_{i j k}$,

$\sigma\left(\delta_{i j}\right)=\sqrt{\frac{1}{M-1} \sum_{k=1}^{M}\left(\delta_{i j k}-\overline{\delta_{i j}}\right)^{2}}$,

where the variable $M$ can be taken as a daily, monthly, annual or other value. It is common to express the mean relative difference based on the entire study period. A relative difference of zero refers to a station that is representative of the mean soil moisture value, where high and low values represent sites that are consistently wet or dry, respectively, compared to the mean. In order to better select sampling locations that were both representative of the mean and had low variability Jacobs et al. (2004) proposed the combination of $\sigma\left(\delta_{i j}\right)$ and $\delta_{i j}$ into the root mean square error measure:

$\operatorname{RMSE}_{i}=\sqrt{{\overline{\delta_{i j}}}^{2}+\sigma\left(\delta_{i j}\right)^{2}}$.

\section{Results and discussion}

The soil moisture in the Hamilton-Halton Watershed follows a seasonal cycle, with temperature and precipitation patterns seen in Fig. 2 and seasonal mean soil moisture presented in Table 3. While the precipitation is relatively evenly distributed throughout the year, during the winter months there is little evapotranspiration and precipitation tends to accumulate on the surface as snow. The spring thaw results in thorough wetting of the soil, until the late-spring and summer temperature increase causes a net dry-down of the soil. Thus, there are seasonal periods of wetting from the late fall to early spring months followed by a drying period from late spring to early fall. The notable exception to this pattern in Table 3 is the soil moisture at depths greater than 50 and $70 \mathrm{~cm}$ at GR/OR and Kelso, respectively, where the autumn experiences a slight net loss from the previous season. Close analysis (results not shown) reveal this secondary dry-down is the result of dry autumns in 2007 and 2009 (Table 1) skewing the temporal statistics. The variability in the surface soil moisture dampened the impact of these dry years in the statistics of the upper soil layers. Since the soil moisture data of the McMaster Mesonet have been collected onward from 2006, the dataset covers several unseasonably wet and dry periods and numerous wetting and drying events, which makes the dataset especially useful for hydrological analysis. Despite the advantages of a continuous dataset, a potential limitation must be noted with respect to freezing soil conditions. The Hamilton-Halton Watershed experiences mild winters in comparison to much of Canada, and periodic freezing and thawing are experienced throughout the winter months, especially in the upper soil layers. Freezing conditions are known to impact TDR measurements (Flerchinger et al., 2006; Kahimba and Sri Ranjan, 2007), an effect which is not accounted for directly herein, or in the native McMaster Mesonet dataset. Due to the low variability of soil moisture, near saturated conditions and comparatively mild conditions throughout the winter season, freezing is not expected to substantially impact the data or analysis. However, further research and data collection is required to confirm this assumption.

The further soil moisture data analyses conducted herein are only for the 10,20 and $50 \mathrm{~cm}$ depths using the data from the CS616 TDR probes, as soil moisture observations are available for every site and station at these depths. The following sections will present the results of the spatio-temporal and temporal stability analysis. First, the monthly mean and standard deviation will be discussed with links made to the local soil moisture state and variability as a result of local ground cover and topography. The temporal stability analysis will follow, focusing on seasonal trends, temporal consistency of the mean relative difference ranks and the time required for spatial organization to return following a disturbance.

\subsection{Spatio-temporal analysis}

A time series of the mean daily soil moisture in the top $50 \mathrm{~cm}$ is shown in Fig. 6, along with the precipitation at each site. As previously noted, the soil moisture exhibits seasonality, with dry periods during summers and recharge of the soil moisture during the winter and spring. The distribution of the soil moisture about the temporal mean shows the temporal soil moisture to be negatively skewed $(\mathrm{GR}=-0.89$; $\mathrm{OR}=-0.97 ; \mathrm{K} 1=-0.90 ; \mathrm{K} 2=-1.02$ ), largely resulting from summer dry-down, particularly in 2007 and 2011, and the upper boundary imposed by saturation. The poor drainage and low infiltration of $\mathrm{K} 1$ and $\mathrm{K} 2$ results in longer periods near the saturation boundary, whereas GR and OR have higher infiltration and topographic runoff, resulting in a more rapid transition of the soil moisture state. The spatial variability tends to be relatively uniform through time at all sites, although this is somewhat visually masked by the vertical transitions in Fig. 6. The greatest spatial variability, as represented by the shaded area, tends to occur during periods with little transitions, or the plateaus in Fig. 6. The greater 
Table 3. Mean soil moisture for Winter (December, January, February), Spring (March, April, May), Summer (June, July, August) and Fall (September, October, November), and the average change between seasons at each site and depth.

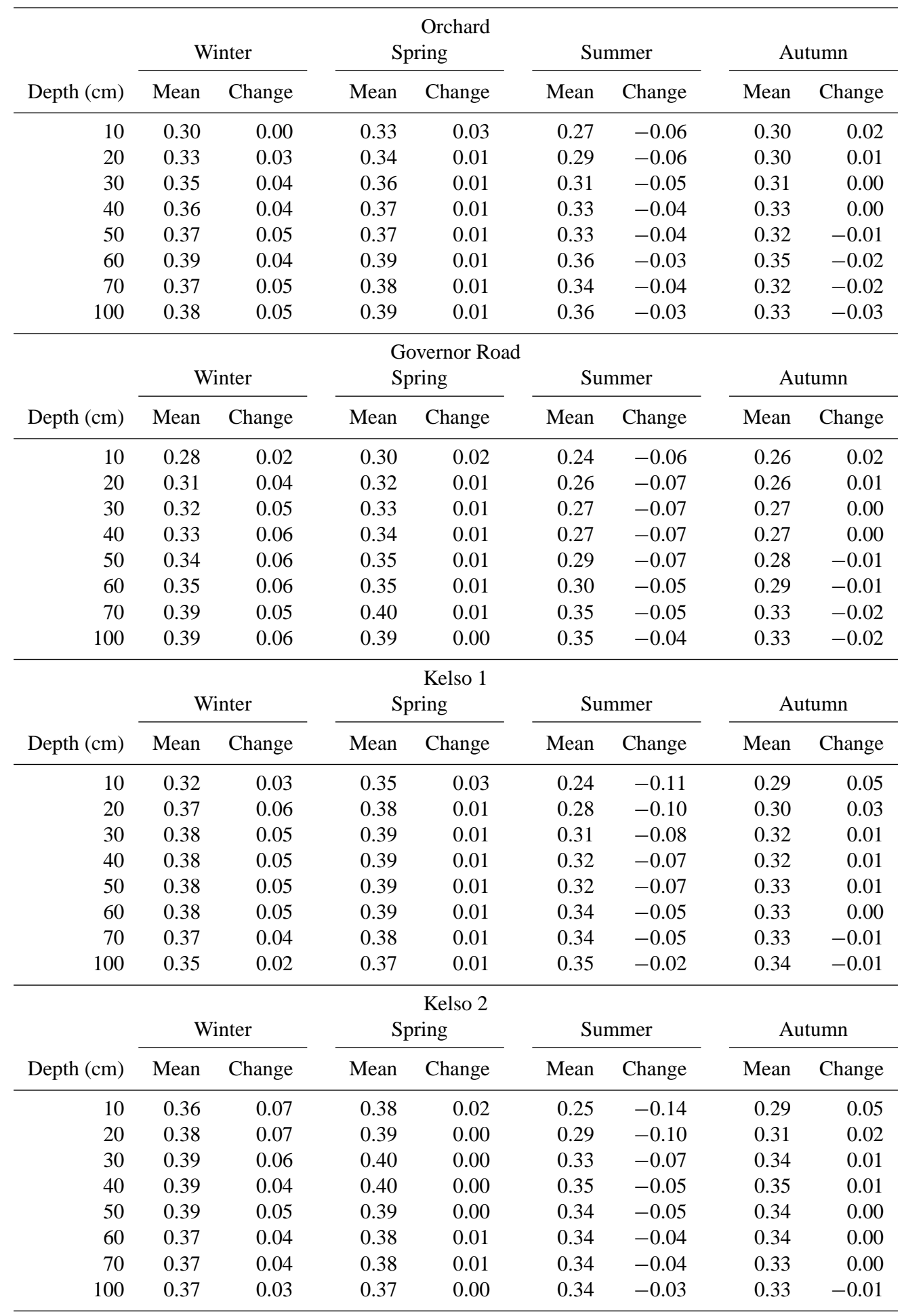

standard deviation during the non-transitional periods is the result of the spatial heterogeneity induced by geographic factors, such as depressions between hummucks at $\mathrm{K} 1$ and $\mathrm{K} 2$ storing water, or the redistribution of water to valleys at GR.
Figure 7 shows the relationship between the spatial mean and variance of soil moisture for each site and depth. At the 10 and $20 \mathrm{~cm}$ depths variability is highest at intermediate quantities of soil moisture at GR and OR, resulting in a slight 


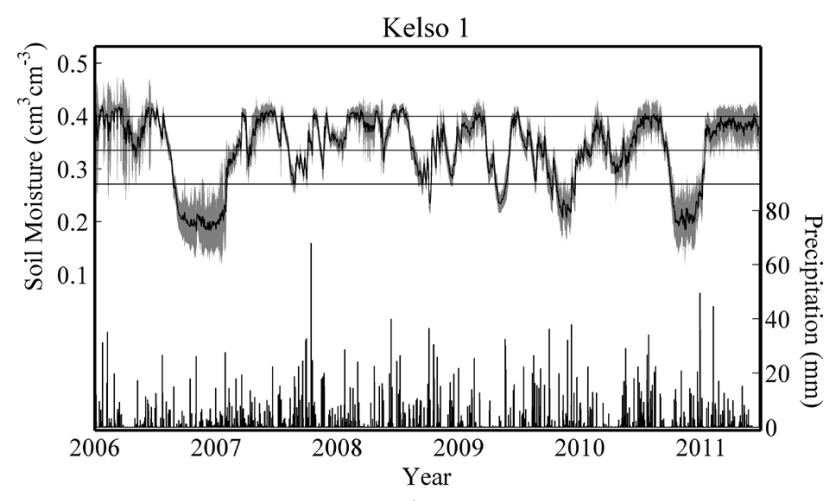

concave down parabolic relationship. At $\mathrm{K} 1$ and $\mathrm{K} 2$ variability generally decreases with increasing soil moisture. The concave down relationship was also found by Famiglietti et al. (2008) at extents greater than $800 \mathrm{~m}$, whereas the decreasing mean-variance relationship of Kelso has been more often found at the field scale (Brocca et al., 2010, 2007; Western et al., 2004; Hupet and Vanclooster, 2002), particularly in humid climates (Brocca et al., 2007). The concave down relationship at GR and OR likely results from topographic redistribution, an influence under-represented in hillslope-scale studies, and suggests that topography is a primary control and climate a secondary control of the change in variability with mean soil moisture state. Soil moisture at the 30 and $50 \mathrm{~cm}$ depths became less variable as soil moisture increased, however, the relatively high soil moisture content at these depths resulted in few observations where the mean moisture content was less than $0.25 \mathrm{~cm}^{3} \mathrm{~cm}^{-3}$, the range where variability decreased in the surface measurements at GR and OR.

Since the soil moisture in the watershed exhibits seasonality, the data have been aggregated on a monthly basis for the years 2007 to 2011 and analysed as spatial soil moisture patterns. The seasonal (monthly) mean and seasonal (monthly) standard deviation of soil moisture for each site can be seen in Fig. 8 and Supplement 1, respectively, as contour plots, which were created by interpolating the soil moisture values between points. For the purposes of making physical interpretation of the soil moisture patterns, the results will be presented as first an inter-site comparison making broad generalizations, and then intra-site comparisons making note of specific anomalies and patterns.

Both K1 and K2 have uniformly distributed soil moisture at all depths and are persistently wetter than the other sites. This results from the lower infiltration capacity and flat topography at this site. Also, the hummocky terrain provides many small depressions in which surface water is stored. OR also has a relatively uniform soil moisture pattern at all depths, although there is a marked spatial pattern at the 10 and $20 \mathrm{~cm}$ depths resulting from the sloping terrain. GR has the most variability in soil moisture pattern during all months resulting from the complex topography and vegetation. All sites experience the highest variability (standard deviation) during the month of January, which is believed to be the result of freeze-thaw processes with temperature fluctuations around $0{ }^{\circ} \mathrm{C}$ causing sporadic redistribution of soil moisture, and inducing errors in the TDR measurements. The lowest variability is during the spring season, when the soil is consistently wet due to snowmelt and low evapotranspiration. During the summer months there is moderate variability brought on by wetting and drying cycles.

In general, the results of the soil moisture analysis are con-

6. Daily time series of mean soil moisture in the top $50 \mathrm{~cm}$ (black line) and precipitation (bars) for the McMaster Mesonet. The middle horizontal lines represent the mean of all observations at each site and one standard deviation, whereas the grey shaded area represents the spatial standard deviation for each sampling day.

sistent with previous studies (Famiglietti et al., 1998), which found that there tends to be low soil moisture values and high variability at the top of slopes and high soil moisture and low variability at the bottom of slopes, with moderate values mid-slope. This pattern was also present at $\mathrm{K} 1$ and $\mathrm{K} 2$, 

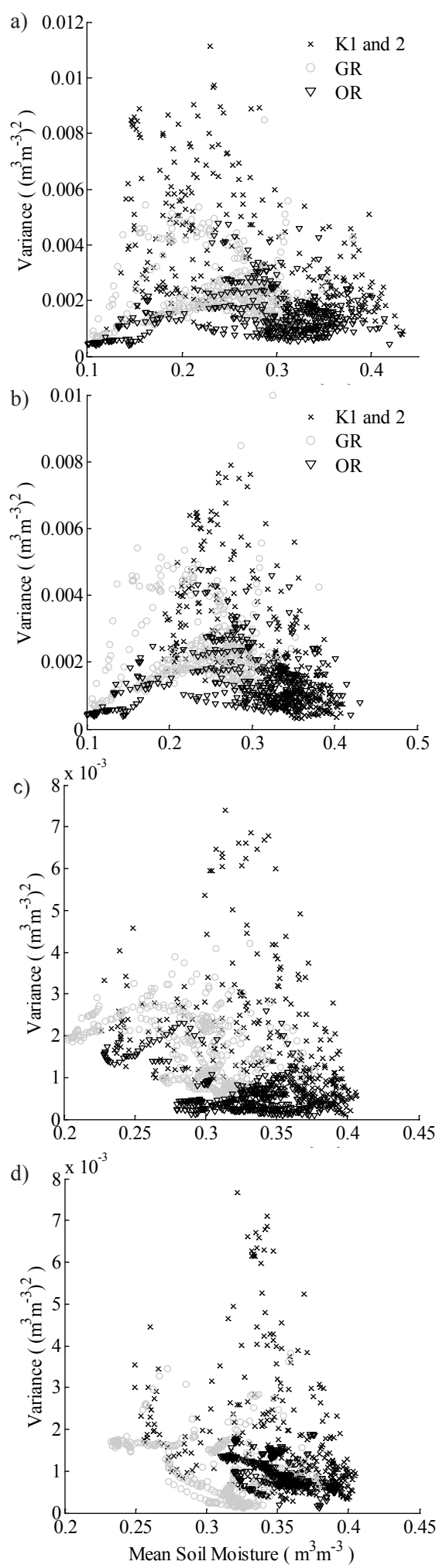

Fig. 7. Relationship between mean soil moisture and variance for the McMaster Mesonet sites at depths of (a) $10 \mathrm{~cm}$, (b) $20 \mathrm{~cm}$, (c) $30 \mathrm{~cm}$ and (d) $50 \mathrm{~cm}$. where there are few prominent terrain features, with the notable exceptions of a small embankment at the south-east of $\mathrm{K} 1$ and a hill in the north-east of K2. These features result in lower mean soil moisture, which is particularly prominent during the summer and fall months and result in the greatest contrast in standard deviations during the winter months. The slope pattern in Kelso is also consistent, although somewhat muted, to a depth of $50 \mathrm{~cm}$, however it declines at 70 to $100 \mathrm{~cm}$ (results not shown). This pattern is also generally present at OR, with the exceptions of OR-1, which has low soil moisture and high variability but is located mid-slope. This anomaly results from a combination of a slight depression in the surface at OR-1 temporarily storing water, and decreased vegetation density due to human disturbance and a protecting fence. Similarly, OR-5 and 8 are located on the upper- and mid-slope, respectively, and have lower mean and more highly variable soil moisture than expected. At OR-8 this results from the sensor being located near a tree, whereas OR-5 is on a side-slope facing a roadway, where drainage to the road side is expected. While still present, the impact of the minor surface features are not as prevalent at the 20 and $50 \mathrm{~cm}$ depths suggesting that, at lower depths, soil moisture is more representative of general patterns in the landscape. At GR, stations 7 and 4 have low mean soil moisture and moderate to high variability due to their location near the crown of a hill. Similarly, the higher moisture content present in the valleys is consistent with previous findings (Famiglietti et al., 1999) and demonstrates the importance of topographic redistribution at small-scales and the long correlation length of variability induced by topography.

\subsection{Temporal stability analysis}

The temporal stability of a station refers to the rank of a station relative to the mean soil moisture state at a particular site. It has often been noted that while absolute soil moisture changes, the ranking of soil moisture at a particular location with respect to the mean value is relatively constant (Vachaud et al., 1985; Martinez-Fernandez and Ceballos, 2003; Cosh et al., 2004; Vivoni et al., 2008). Here, the temporal stability is analysed for the entire length of record, amalgamating the Kelso stations as well as GR and OR due to proximity, and each site has been analysed on a seasonal (monthly) basis for the 10,20 and $50 \mathrm{~cm}$ depths.

\subsubsection{Long-term temporal stability}

Figure 9 shows the results of the temporal stability analysis at each depth for the entire duration of the dataset. Stations that are consistently positive are wet with respect to the spatial mean soil moisture, whereas negative values correspond to dry stations. RMSE, represented as the dotted line, gives an indication of stations which are both stable and representative of the mean. There is generally greater variability in the relative difference of the 10 and $20 \mathrm{~cm}$ depths than the $50 \mathrm{~cm}$ 

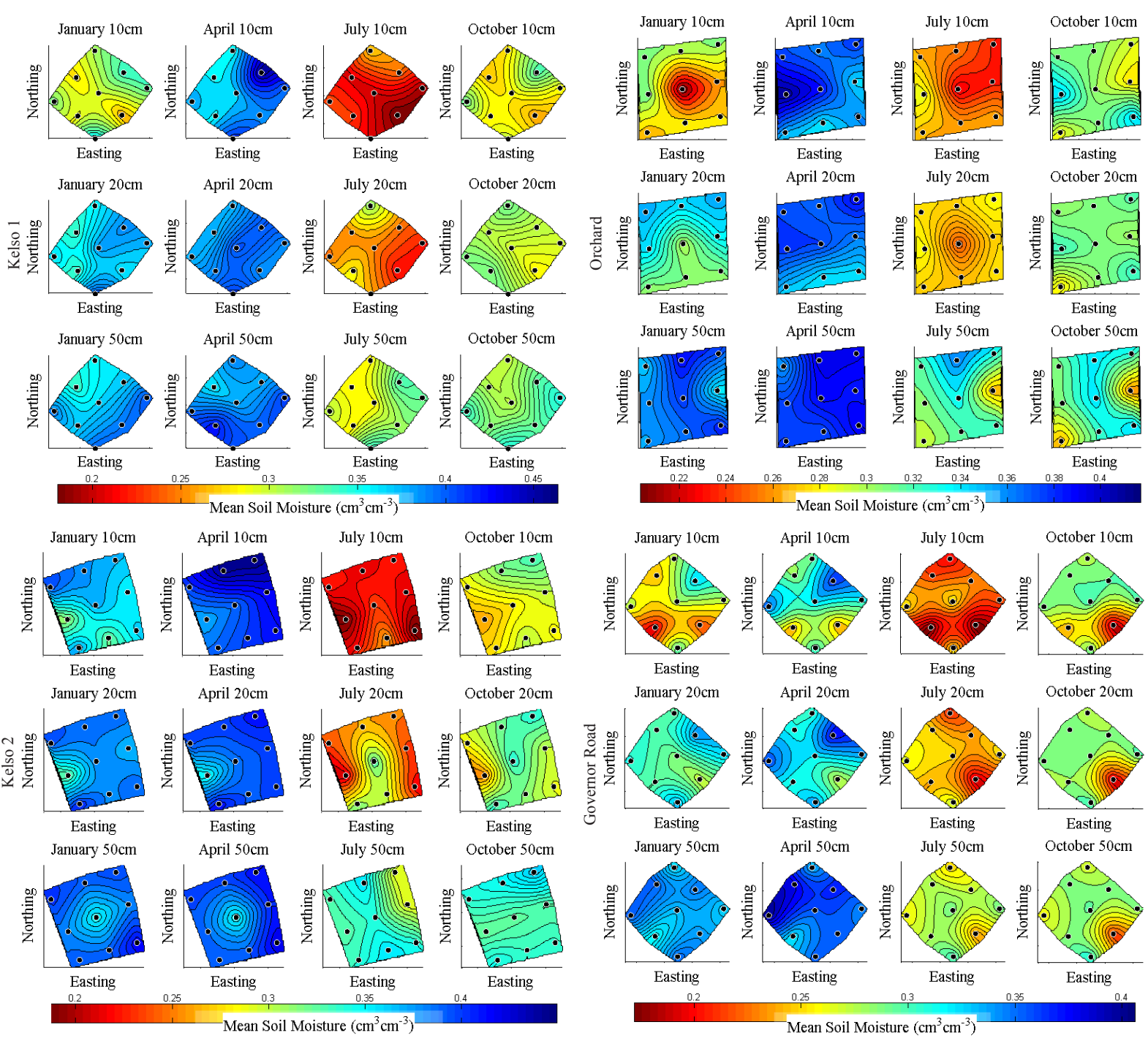

Fig. 8. Seasonal (monthly) mean soil moisture of McMaster Mesonet sites. The contour plots are created by a natural neighbour interpolant between observed soil moisture points. A complimentary contour plot of seasonal (monthly) standard deviation can be found in the Supplement.

depth, showing that variability is greatest near the surface (Choi and Jacobs, 2007) and that rank stability is less important with depth (Heathman et al., 2009). The relative difference is generally consistent across depths, where only minor changes in rank position occur. Exceptions to this are the result of small-scale features, where vegetation roots, canopy or depression storage impacts the relative difference pattern more strongly at certain depths (Famiglietti et al., 1998). OR1, GR-9 and K-19 are examples of this, where the position of the surface and subsurface soil moisture relative to the mean changes with depth. The distribution of both OR and GR stations throughout the relative difference plot suggests that topography is more important in determining the spatial distribution of soil moisture than vegetation which was also noted by Cosh et al. (2004) in the Walnut Creek Experimental
Watershed. Generally, the stations with the highest rank are located at the bottom of the slopes, whereas stations with the lowest rank are located in upslope areas. This is also true of the Kelso sites, where the change in elevation is minor. However, the relatively flat topography at Kelso results in less stability in the spatial distribution of soil moisture than is observed at OR and GR, as indicated by the standard deviation of the relative difference.

\subsubsection{Seasonal temporal stability}

The seasonal spatial patterns of the mean relative difference are similar to the mean soil moisture patterns found in Fig. 8, and so will not be reproduced here. For the flat/gently sloping terrain at $\mathrm{K} 1, \mathrm{~K} 2$ and $\mathrm{OR}$ the relative rank of each 

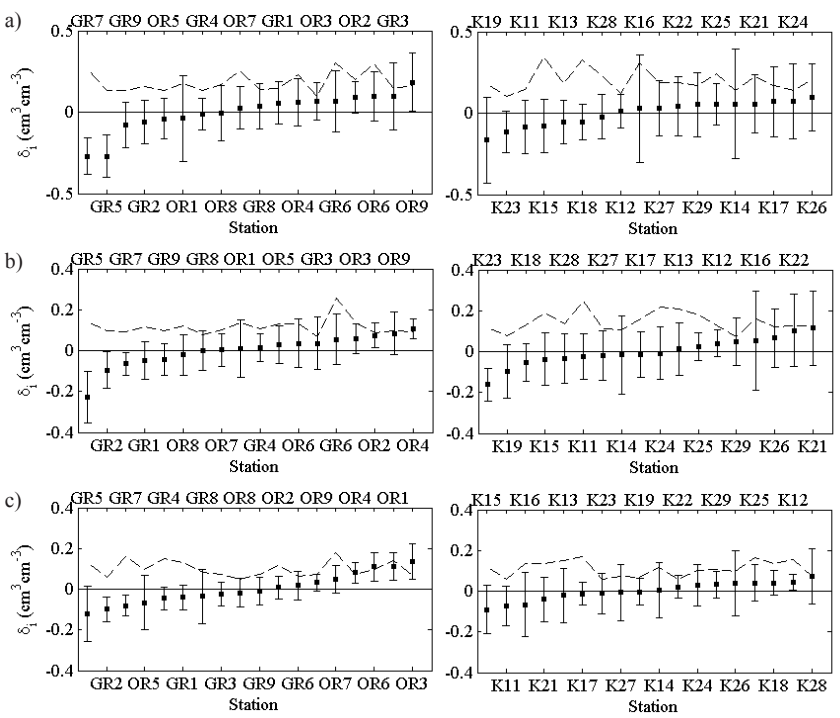

Fig. 9. Mean relative difference for the entire study period at the McMaster Mesonet sites at depths of (a) $10 \mathrm{~cm}$, (b) $20 \mathrm{~cm}$, (c) $50 \mathrm{~cm}$. GR and OR are grouped due to their close spatial proximity, as are $\mathrm{K} 1$ and $\mathrm{K} 2$. The bars represent one standard deviation of the relative difference and the dotted line shows the RMSE from Eq. (9).

station remains generally consistent throughout time. Unlike the other sites, there is a marked change in temporal rankings at GR throughout the year as seen in Fig. 10. At the monthly scale, a similar $\overline{\delta_{i j}}$ may result in some stations changing ranked position. For example, in Fig. 10 stations 7 and 5 both represent dry stations but have changed rank order as the driest station. Often due to the overlap in variance of $\overline{\delta_{i j}}$, especially for mean representative sites, the change in station rank order is not meaningful $(\alpha=0.05)$. An example is station 4 in Fig. 10, where the station is always representative of the mean or median value but changes rank order.The relative difference for the stations at GR have generally low variability, but shift at the 10 and $20 \mathrm{~cm}$ depths. The greatest change in rank occurs at GR-3 and 4. During the winter and spring the downslope station (GR-3) is consistently the highest ranked station (wet), however, during the summer and fall months GR-3 becomes mid-ranked and is more representative of the site mean soil moisture. A noticeable feature in Fig. 10, is the presence of a definitive slope or stronger ranking during the spring and summer periods. In comparison, the October mean relative difference plot shows most stations, except for GR-5 and 7, have a relatively flat trend.

It has been suggested that temporal stability analysis can be used to select monitoring sites representative of the field/catchment mean (Brocca et al., 2010; Jacobs et al., 2004). The results show the need for caution when using this approach as sites representative of the mean under a particular set of soil conditions (seasons) were not representative during all time periods, and the suggestion to use
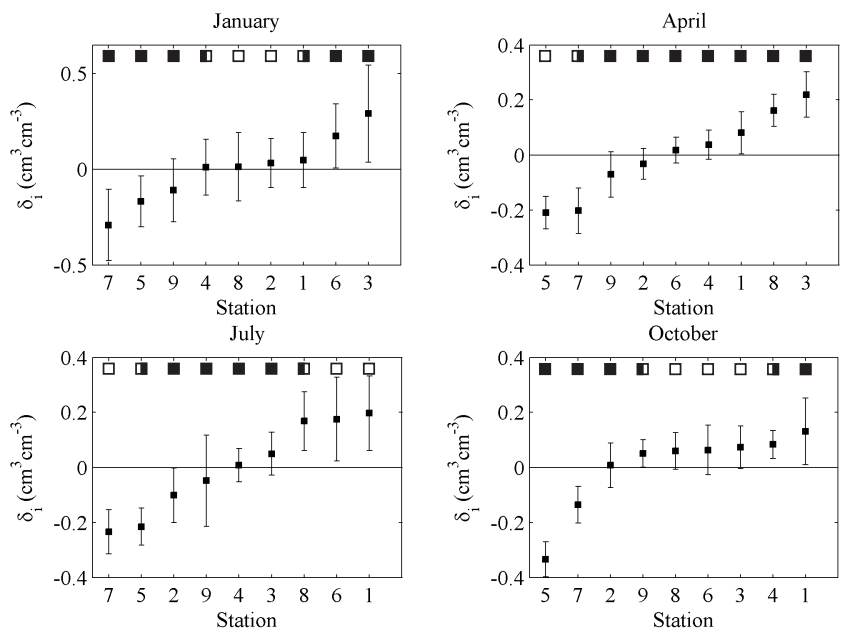

Fig. 10. Seasonal temporal stability at GR at a depth of $10 \mathrm{~cm}$. The boxes show the mean relative difference and the bars one standard deviation of the relative difference. The white half boxes at the top of the figure show where a station is similar $(\alpha=0.05)$ to its neighbour on the respective side.

multiple mid-ranked sites is prudent. The change in rank of the wet stations (GR-3) is unlike other findings where wet and dry sites are stable (Cosh et al., 2008; Jacobs et al., 2004; Martinez-Fernandez and Ceballos, 2003) and indicates a transition in influences controlling spatial distribution, where topography dominates in wet conditions (Heathman et al., 2009; Western and Bloschl, 1999; Famiglietti et al., 1998) and vegetation and soil texture dominate in dry conditions (Vivoni et al., 2008; Hupet and Vanclooster, 2002). The demonstrated "seasonality" should be taken into account when using temporal stability at the hillslope to catchment scale in complex terrain, especially where vegetation changes may influence soil moisture variability (Hupet and Vanclooster, 2002).

Since the majority of soil moisture monitoring programs have been carried out in meadows and agricultural fields (Famiglietti et al., 1998, 1999; Brocca et al., 2007; Heathman et al., 2009; and others), GR offers unique insight into the importance of higher density vegetation in determining the soil moisture spatial pattern. It has been shown that at small-scales precipitation increases homogeneity with wetting, which is subsequently redistributed by topography, soil texture and evapotranspiration following wetting in areas with low tree density (Wilson et al., 2003; Famiglietti et al., 2008), and is consistent with results at K1, K2 and OR. However, GR is covered by a mix of forested areas and open meadows, resulting in vegetation causing a seasonal organization in soil moisture during wetting. The seasonality of the mean relative difference patterns shows the possibility of temporal instability in seasonal climates such as those present in midlatitudes. 
Table 4. Characteristics of analysed rain events. If a rain event is broken into two distinct rainfalls, the amount of rain in each is separated, and the duration is separated as first rainfall duration, gap length, and second rainfall duration.

\begin{tabular}{llll}
\hline $\begin{array}{l}\text { Rain } \\
\text { Event }\end{array}$ & Date and Time (LT) & $\begin{array}{c}\text { Amount of } \\
\text { Rain (mm) }\end{array}$ & $\begin{array}{c}\text { Duration } \\
\text { (hours) }\end{array}$ \\
\hline \multicolumn{4}{c}{ Kelso (K1) } \\
1 & 11 Jul 2009 - 09:00-11:00 h & 6.2 & 3 \\
2 & 28-29 Aug 2009-22:00-11:00 h & $22.1 / 0.1$ & $8 / 5 / 1$ \\
\hline 3 & 15-16 Mar 2011-23:00-10:00 h & 6.1 & 12 \\
4 & 3 Aug 2011-03:00-22:00 h & $8.6 / 1.6$ & $4 / 10 / 6$ \\
\hline \multicolumn{5}{c}{ Dundas Valley (GR \& OR) } \\
1 & 11 Jul 2009-09:00-14:00 h & $9.0 / 0.1$ & $2 / 1 / 1$ \\
2 & 28-29 Aug 2009-22:00-20:00 h & $32.2 / 3.2$ & $11 / 11 / 1$ \\
3 & 15-16 Mar 2011 -22:00-10:00 h & 4.8 & 13 \\
4 & 3 Aug 2011 - 14:00-24:00 h & $1.6 / 1.0$ & $2 / 3 / 6$ \\
\hline
\end{tabular}

\subsubsection{Persistence of ranks}

The fundamental concept of temporal stability is the persistence of the relative spatial pattern of soil moisture, which has already been demonstrated to be more distinct during the spring and summer months. However, it is known that precipitation has a homogenizing effect on the soil moisture pattern and can disrupt the temporal stability pattern at all scales (Wilson et al., 2003; Famiglietti et al., 2008), which may hamper the use of temporal stability in hydrological applications (Loew and Mauser, 2008). Due to the collection of hourly data at the McMaster Mesonet a preliminary assessment of the potential of precipitation to impact temporal stability can be performed. Four rain storms were selected to analyse the length of interruption of the temporal stability pattern and to provide insight as to the duration required for the dominant soil moisture pattern to re-emerge. The four rain events were selected based on two primary criteria: (i) significant rainfall being present at both Kelso (K1) and Dundas Valley (GR \& OR) and (ii) a sufficient period without rain is present both prior to and following the rain event so as to allow for the presence of a stable soil moisture pattern before and after the rain. The details of the four selected storms can be found in Table 4, and the relative difference for storm 2 is shown in Fig. 11. Only storm 2 at $10 \mathrm{~cm}$ is presented herein for brevity and $\mathrm{K} 2$ is ignored because of the close proximity and similar topography to K1.

Due to the dry conditions prior to rainfall and the sloping topography, rain event 1 did not have a distinguishable impact on the soil moisture pattern at any site, however it did cause noticeable wetting at $\mathrm{K} 1$. While some change occurred immediately following the precipitation, the peak of the impact at $\mathrm{K} 1$ occurred 24 to $40 \mathrm{~h}$ following the rain event as ponded water slowly infiltrated the poorly drained soil. Rain storm 2 added significantly more water to the soil than the other storms and had a strong wetting effect at all sites, with the greatest impact at the $20 \mathrm{~cm}$ depth. At K1, the storm
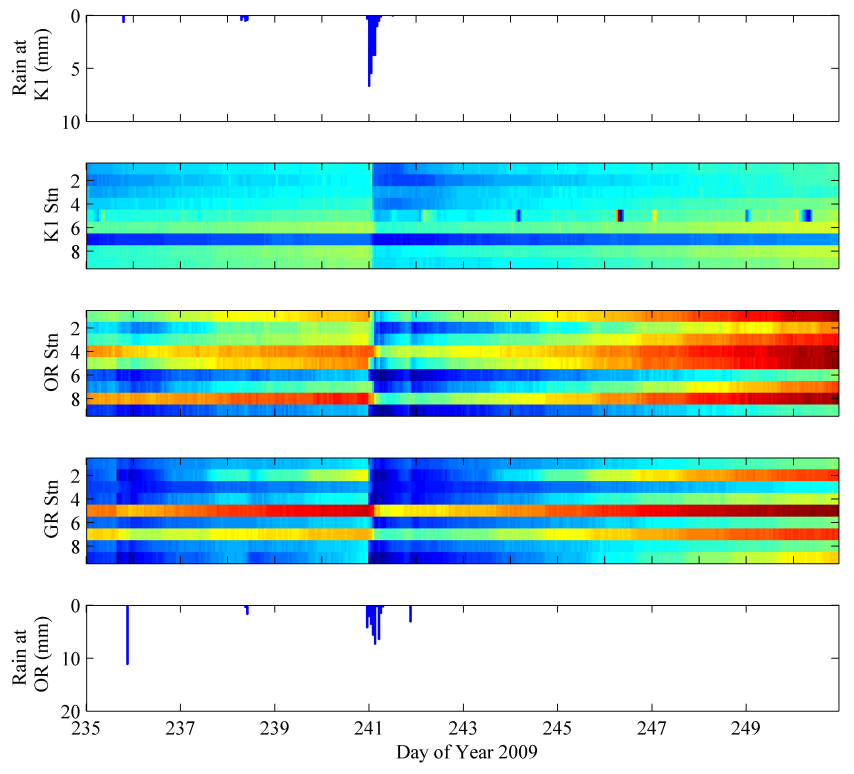

Fig. 11. Analysis of the mean relative difference before and after rain event 2 at a depth of $10 \mathrm{~cm}$ at $\mathrm{K} 1, \mathrm{OR}$ and GR. The colour scale changes from red (dry) to blue (wet) where mean soil moisture values $\left(\delta_{j k}=0\right)$ are cyan. For visual interpretation the colour map is stretched for each image and colour values are relative.

caused wetting of the already moist soil, but did not disrupt the relative ranks of the spatial soil moisture pattern. Due to the relatively higher clay content and flat topography the impact of the rain also persisted longer at K1 compared to the other sites, with the impact at some stations lingering for as many as 6 days after the rainfall. Similarly, at OR the rain caused a large increase in the amount of soil moisture but did not lead to the homogenization of soil moisture, and thus the persistent pattern was still present. At GR, stations 5 and 7, which are under dense vegetation and on the hilltop, respectively, experienced some wetting but were less impacted than other stations and were stable as relatively dry sites during that time period. The remaining GR sites, which were still wet from a previous rainfall, became homogenous, thus disrupting the temporal stability pattern. The relative soil moisture pattern began to re-emerge within 18 to $24 \mathrm{~h}$ following the peak rainfall. At all sites the spatial pattern had the greatest disruption, which was sustained for the longest period of time at the $20 \mathrm{~cm}$ depth. The lack of surface evaporation and already greater homogeneity at this depth caused the effect of the precipitation to linger for approximately 2 days longer than at the $10 \mathrm{~cm}$ depth. While there was some wetting, the rainfall did not affect the spatial soil moisture pattern at $50 \mathrm{~cm}$ at any site. The rainfall from events 3 and 4 did result in an increase in soil moisture but was not strong enough to impact the relative spatial pattern at any site or depth with the exception of $\mathrm{OR}$ at $20 \mathrm{~cm}$. This site was already wet from snow melt and spring rain and so additional water did disrupt the persistence of the spatial pattern. 
These results lead to several insights about the nature of temporal stability following rain. It should first be noted that without the soil being wet prior to the addition of water, the temporal stability of the soil moisture was not impacted without the addition of a considerable amount of rain $(>20 \mathrm{~mm})$. The normal rainfall amounts for the watershed ( 2 to $10 \mathrm{~mm}$ ) did not cause enough homogenization to affect the temporal (rank) stability pattern, even at the flat and poorly drained Kelso site. Also important is the impact of topography and vegetation as was best noted at the GR site. Dense vegetation resulted in high interception leaving GR-5 persistently dry, whereas GR-4 is located on an uphill area and so while its rank was impacted by rainfall, the higher potential for soil water redistribution caused that station to recover its relative rank with only a short delay.

\section{Conclusions}

The McMaster Mesonet was introduced and spatio-temporal and temporal stability analysis carried out in order to characterize the soil moisture patterns representative of the Mesonet datasets. The McMaster Mesonet consists primarily of the infrastructure necessary to monitor hourly soil moisture profiles using a high-spatial-resolution TDR array at four sites, as well as associated hydro-meteorological stations. The sites represent different topographies and vegetation covers and provide some insight into the seasonal patterns of soil moisture experienced in the climatic context of the southern Great Lakes Basin.

Analysis of the data reveals a moderately well-organized soil moisture pattern which is temporally persistent on a seasonal basis. Topography represents a dominant control of the soil moisture pattern in wet to intermediate soil moisture conditions, whereas vegetation, soil texture and microtopography have greater influence in intermediate-dry conditions. The spatial pattern at subseasonal scales was persistent in most conditions, unless a substantial rainfall/snowmelt resulted in homogenization of the soil moisture. Following disturbance by precipitation, the relative soil moisture pattern re-emerged after 18 to $24 \mathrm{~h}$ of drying and the moisture added by the precipitation was removed within 4 to 7 days. At the subseasonal timescale, soil moisture variability was the greatest at a depth of $10 \mathrm{~cm}$, and was lowest at a depth of $50 \mathrm{~cm}$. The spatial pattern of soil moisture at a depth of $20 \mathrm{~cm}$ was more representative of mean topography, where the influence of hummocks and small depressions at the surface was not as prevalent.

These types of analyses of soil moisture patterns at multiple temporal scales are only possible where monitoring is continuous and of a long duration and high temporal resolution such as the McMaster Mesonet. Unlike studies with shorter duration or random sampling periods, these results lead to the conclusion that hydrological applications of the temporal (rank) stability concept should account for temporal (seasonal) changes, especially in complex terrain. Where topography was simple, as at Kelso, spatial variability was greatest in dry conditions due to storage in hummocks and differences in vegetation cover. At GR and OR, variability was highest at intermediate soil moisture conditions as topography and vegetation both provided a strong control on the soil moisture spatial pattern.

The long-term, high-spatial-resolution hourly soil moisture profiles recorded by the McMaster Mesonet can provide insights into the nature of this important hydrological state variable. Future work will use data from the McMaster Mesonet for data assimilation to improve hydrological forecasts, downscaling and validation of remote sensing soil moisture products and to study the complex interactions between climate, soil, topography and vegetation.

\section{Supplementary material related to this article is available online at: http://www.hydrol-earth-syst-sci.net/ 17/1589/2013/hess-17-1589-2013-supplement.pdf.}

Acknowledgements. The authors would like to gratefully acknowledge the help of G. Dumedah, J. Samuel, X. Long and others for helping with the data downloading and ongoing maintenance of the McMaster Mesonet dataset. We would also like to thank two anonymous referees for their comments which have helped to improve this manuscript. The McMaster Mesonet and this work are partially supported by the Canadian Foundation for Innovation (CFI), the Ontario Innovation Trust (OIT) and the Natural Sciences and Engineering Research Council (NSERC) of Canada. The authors would also like to thank the Hamilton Conservation Authority and Conservation Halton for permitting use of their land for the research experiment.

Edited by: Y. Fan

\section{References}

Alavi, N., Berg, A. A., Warland, J. S., Parkin, G., Verseghy, D., and Bartlett, P.: Evaluating the Impact of Assimilating Soil Moisture Variability Data on Latent Heat Flux Estimation in a Land Surface Model, Can. Water Resour. J., 35, 157-172, 2010.

Albergel, C., Rüdiger, C., Pellarin, T., Calvet, J.-C., Fritz, N., Froissard, F., Suquia, D., Petitpa, A., Piguet, B., and Martin, E.: From near-surface to root-zone soil moisture using an exponential filter: an assessment of the method based on in-situ observations and model simulations, Hydrol. Earth Syst. Sci., 12, 1323-1337, doi:10.5194/hess-12-1323-2008, 2008.

Blöschl, G. and Sivapalan, M.: Scale issues in hydrological modelling: A review, Hydrol. Process., 9, 251-290, 1995.

Bosch, D. D., Lakshmi, V., Jackson, T. J., Choi, M., and Jacobs, J. M.: Large scale measurements of soil moisture for validation of remotely sensed data: Georgia soil moisture experiment of 2003, J. Hydrol., 323, 120-137, doi:10.1016/j.jhydrol.2005.08.024, 2006. 
Brocca, L., Morbidelli, R., Melone, F., and Moramarco, T.: Soil moisture spatial variability in experimental areas of central Italy, J. Hydrol., 333, 356-373, doi:10.1016/j.jhydrol.2006.09.004, 2007.

Brocca, L., Melone, F., Moramarco, T., and Singh, V. P.: Assimilation of Observed Soil Moisture Data in Storm Rainfall-Runoff Modeling, J. Hydrol. Eng., 14, 153-165, doi:10.1061/(ASCE)1084-0699(2009)14:2(153), 2009.

Brocca, L., Melone, F., Moramarco, T., and Morbidelli, R.: Spatial-temporal variability of soil moisture and its estimation across scales, Water Resour. Res., 46, W02516, doi:10.1029/2009WR008016, 2010.

Bronstert, A. and Bárdossy, A.: The role of spatial variability of soil moisture for modelling surface runoff generation at the small catchment scale, Hydrol. Earth Syst. Sci., 3, 505-516, doi:10.5194/hess-3-505-1999, 1999.

Campbell Scientific: On-Line Estimation of Grass Reference Evapotranspiration with the Campbell Scientific Automated Weather Station: App Note Code: 4-D. Logan, UT, 1999.

Ceballos, A., Scipal, K., Wagner, W., and Martinez-Fernandez, J.: Validation of ERS scatterometer-derived soil moisture data in the central part of the Duero Basin, Spain, Hydrol. Process., 19, 1549-1566, doi:10.1002/hyp.5585, 2005.

Chen, Y.: Letter to the editor on "Rank stability or temporal stability", Soil Sci. Soc. Am. J., 70, 306-306, doi:10.2136/sssaj2005.02901, 2006.

Choi, M. and Jacobs, J. M.: Soil moisture variability of root zone profiles within SMEX02 remote sensing footprints, Adv. Water Resour., 30, 883-896, doi:10.1016/j.advwatres.2006.07.007, 2007.

Cosh, M. H., Jackson, T. J., Bindlish, R., and Prueger, J. H.: Watershed scale temporal and spatial stability of soil moisture and its role in validating satellite estimates, Remote Sens. Environ., 92, 427-435, doi:10.1016/j.rse.2004.02.016, 2004.

Cosh, M. H., Jackson, T. J., Moran, S., and Bindlish, R.: Temporal persistence and stability of surface soil moisture in a semi-arid watershed, Remote Sens. Environ., 112, 304-313, doi:10.1016/j.rse.2007.07.001, 2008.

Das, N. N., Mohanty, B. P., Cosh, M. H., and Jackson, T. J.: Modeling and assimilation of root zone soil moisture using remote sensing observations in Walnut Gulch Watershed during SMEX04, Remote Sens. Environ., 112, 415-429, doi:10.1016/j.rse.2006.10.027, 2008.

Dorigo, W. A., Wagner, W., Hohensinn, R., Hahn, S., Paulik, C., Xaver, A., Gruber, A., Drusch, M., Mecklenburg, S., van Oevelen, P., Robock, A., and Jackson, T.: The International Soil Moisture Network: a data hosting facility for global in situ soil moisture measurements, Hydrol. Earth Syst. Sci., 15, 1675-1698, doi:10.5194/hess-15-1675-2011, 2011.

Dumedah, G. and Coulibaly, P.: Evaluation of statistical methods for infilling missing values in high-resolution soil moisture data, J. Hydrol., 400, 95-102, doi:10.1016/j.jhydrol.2011.01.028, 2011.

Famiglietti, J. S., Rudnicki, J. W., and Rodell, M.: Variability in surface moisture content along a hillslope transect: Rattlesnake Hill, Texas, J. Hydrol., 210, 259-281, doi:10.1016/S00221694(98)00187-5, 1998.

Famiglietti, J. S., Devereaux, J. A., Laymon, C. A., Tsegaye, T., Houser, P. R., Jackson, T. J., Graham, S. T., Rodell, M., and van Oevelen, P. J.: Ground-based investigation of soil moisture variability within remote sensing footprints during the Southern Great Plains 1997 (SGP97) Hydrology Experiment, Water Resour. Res., 35, 1839-1851, doi:10.1029/1999WR900047, 1999.

Famiglietti, J. S., Ryu, D., Berg, A. A., Rodell, M., and Jackson, T. J.: Field observations of soil moisture variability across scales, Water Resour. Res., 44, W01423, doi:10.1029/2006WR005804, 2008.

Flerchinger, G. N., Seyfried, M. S., and Hardegree, S. P.: Using soil freezing characteristics to model multi-season soil water dynamics, Vadose Zone J., 5, 1143-1153, doi:10.2136/vzj2006.0025, 2006.

Gillespie, J. E., Wicklund, R. E., and Miller, M. H.: The Soils of Halton County: Report No. 43 of the Ontario Soil Survey. Ontario Department of Agriculture, 80 pp., 1971.

Grayson, R. B. and Western, A. W.: Towards areal estimation of soil water content from point measurements: time and space stability of mean response, J. Hydrol., 207, 68-82, 1998.

Heathman, G. C., Larose, M., Cosh, M. H., and Bindlish, R.: Surface and profile soil moisture spatio-temporal analysis during an excessive rainfall period in the Southern Great Plains, USA, Catena, 78, 159-169, doi:10.1016/j.catena.2009.04.002, 2009.

Hupet, F. and Vanclooster, M.: Intraseasonal dynamics of soil moisture variability within a small agricultural maize cropped field, J. Hydrol., 261, 86-101, doi:10.1016/S0022-1694(02)00016-1, 2002.

Ivanov, V. Y., Fatichi, S., Jenerette, G. D., Espeleta, J. F., Troch, P. A., and Huxman, T. E.: Hysteresis of soil moisture spatial heterogeneity and the "homogenizing" effect of vegetation, Water Resour. Res., 46, W09521, doi:10.1029/2009WR008611, 2010.

Jacobs, J. M., Mohanty, B. P., Hsu, E. C., and Miller, D.: SMEX02: Field scale variability, time stability and similarity of soil moisture, Remote Sens. Environ., 92, 436-446, doi:10.1016/j.rse.2004.02.017, 2004.

Kahimba, F. C. and Sri Ranjan, R.: Soil temperature correction of field TDR readings obtained under near freezing conditions, Can. Biosys. Eng., 49, 1.19-1.26, 2007.

Komma, J., Bloeschl, G., and Reszler, C.: Soil moisture updating by Ensemble Kalman Filtering in real-time flood forecasting, J. Hydrol., 357, 228-242, doi:10.1016/j.jhydrol.2008.05.020, 2008.

Kornelsen, K. and Coulibaly, P.: Comparison of interpolation, statistical and data driven methods for imputation of missing values in a distributed soil moisture dataset, J. Hydrol. Eng., accepted, 2013.

Lebel, T., Cappelaere, B., Galle, S., Hanan, N., Kergoat, L., Levis, S., Vieux, B., Descroix, L., Gosset, M., Mougin, E., Peugeot, C., and Seguis, L.: AMMA-CATCH studies in the Sahelian region of West-Africa: An overview, J. Hydrol., 375, 3-13, doi:10.1016/j.jhydrol.2009.03.020, 2009.

Loew, A. and Mauser, W.: On the disaggregation of passive microwave soil moisture data using a priori knowledge of temporally persistent soil moisture fields, IEEE T. Geosci. Remote Sens., 43, 819-834, doi:10.1109/TGRS.2007.914800, 2008.

Loew, A., Schwank, M., and Schlenz, F.: Assimilation of an L-Band Microwave Soil Moisture Proxy to Compensate for Uncertainties in Precipitation Data, IEEE T. Geosci. Remote Sens., 47, 26062616, doi:10.1109/TGRS.2009.2014846, 2009.

Mahanama, S. P. P., Koster, R. D., Reichle, R. H., and Zubair, L.: The role of soil moisture initialization in subseasonal and seasonal streamflow prediction - A case 
study in Sri Lanka, Adv. Water Resour., 31, 1333-1343, doi:10.1016/j.advwatres.2008.06.004, 2008.

Martinez-Fernandez, J. and Ceballos, A.: Temporal stability of soil moisture in a large-field experiment in Spain, Soil Sci. Soc. Am. J., 67, 1647-1656, 2003.

Merlin, O., Chehbouni, A., Boulet, G., and Kerr, Y.: Assimilation of disaggregated microwave soil moisture into a hydrologic model using coarse-scale meteorological data, J. Hydrometeorol., 7, 1308-1322, doi:10.1175/JHM552.1, 2006.

Minet, J., Laloy, E., Lambot, S., and Vanclooster, M.: Effect of highresolution spatial soil moisture variability on simulated runoff response using a distributed hydrologic model, Hydrol. Earth Syst. Sci., 15, 1323-1338, doi:10.5194/hess-15-1323-2011, 2011.

Mohanty, B. P. and Skaggs, T. H.: Spatio-temporal evolution and time-stable characteristics of soil moisture within remote sensing footprints with varying soil, slope, and vegetation, Adv. Water Resour., 24, 1051-1067, doi:10.1016/S0309-1708(01)000343, 2001.

Mohanty, B. P., Famiglietti, J. S., and Skaggs, T. H.: Evolution of soil moisture spatial structure in a mixed vegetation pixel during the Southern Great Plains 1997 (SGP97) Hydrology Experiment, Water Resour. Res., 36, 3675-3686, doi:10.1029/2000WR900258, 2000a.

Mohanty, B. P., Skaggs, T. H., and Famiglietti, J. S.: Analysis and mapping of field-scale soil moisture variability using highresolution, ground-based data during the Southern Great Plains 1997 (SGP97) Hydrology Experiment, Water Resour. Res., 36, 1023-1031, doi:10.1029/1999WR900360, 2000b.

Mohr, K. I., Baker, R. D., Tao, W. K., and Famiglietti, J. S.: The sensitivity of West African convective line water budgets to land cover, J. Hydrometeorol., 4, 62-76, doi:10.1175/15257541(2003)004<0062:TSOWAC >2.0.CO;2, 2003.

Peters-Lidard, C. D., Pan, F., and Wood, E. F.: A re-examination of modeled and measured soil moisture spatial variability and its implications for land surface modeling, Adv. Water Resour., 24, 1069-1083, doi:10.1016/S0309-1708(01)00035-5, 2001.

Presant, E. W., Wicklund, R. E., and Matthews, B. C.: The Soils of Wentworth County: Report No. 32 of the Ontario Soil Survey. Ontario Department of Agriculture, 72 pp., 1965.

Ryu, D. and Famiglietti, J. S.: Characterization of footprintscale surface soil moisture variability using Gaussian and beta distribution functions during the Southern Great Plains 1997 (SGP97) hydrology experiment, Water Resour. Res., 41, W12433, doi:10.1029/2004WR003835, 2005.

Ryu, D. and Famiglietti, J. S.: Multi-scale spatial correlation and scaling behavior of surface soil moisture, Geophys. Res. Lett., 33, L08404, doi:10.1029/2006GL025831, 2006.
Seneviratne, S. I., Corti, T., Davin, E. L., Hirschi, M., Jaeger, E. B., Lehner, I., Orlowsky, B., and Teuling, A. J.: Investigating soil moisture-climate interactions in a changing climate: A review, Earth-Sci. Rev., 99, 125-161, doi:10.1016/j.earscirev.2010.02.004, 2010.

Torres, R., Dietrich, W. E., Montgomery, D. R., Anderson, S. P., and Loague, K.: Unsaturated zone processes and the hydrologic response of a steep, unchanneled catchment, Water Resour. Res., 34, 1865-1879, 1998.

Vachaud, G., Silans, P. D., Balabanis, P., and Vauclin, M.: Temporal stability of spatially measured soil water probability density function, Soil Sci. Soc. Am. J., 49, 822-828, 1985.

Vanderlinden, K., Vereecken, H., Hardelauf, H., Herbst, M., Martínez, G., Cosh, M., and Pachepsky, Y.: Temporal stability of soil water contents: A review of data and analyses, Vadose Zone J., 11, 4, doi:10.2136/vzj2011.0178, 2012.

Vivoni, E. R., Gebremichael, M., Watts, C. J., Bindlish, R., and Jackson, T. J.: Comparison of ground-based and remotelysensed surface soil moisture estimates over complex terrain during SMEX04, Remote Sens. Environ., 112, 314-325, doi:10.1016/j.rse.2006.10.028, 2008.

Western, A. W. and Bloschl, G.: On the spatial scaling of soil moisture, J. Hydrol., 217, 203-224, doi:10.1016/S00221694(98)00232-7, 1999.

Western, A. W., Zhou, S. L., Grayson, R. B., McMahon, T. A., Bloschl, G., and Wilson, D. J.: Spatial correlation of soil moisture in small catchments and its relationship to dominant spatial hydrological processes, J. Hydrol., 286, 113-134, doi:10.1016/j.jhydrol.2003.09.014, 2004.

Wilson, D. J., Western, A. W., Grayson, R. B., Berg, A. A., Lear, M. S., Rodell, M., Famiglietti, J. S., Woods, R. A., and McMahon, T. A.: Spatial distribution of soil moisture over 6 and $30 \mathrm{~cm}$ depth, Mahurangi river catchment, New Zealand, J. Hydrol., 276, 254274, doi:10.1016/S0022-1694(03)00060-X, 2003.

Wood, E. F., Roundy, J. K., Troy, T. J., van Beek, L. P. H., Bierkens, M. F. P., Blyth, E., de Roo, A., Doell, P., Ek, M., Famiglietti, J., Gochis, D., van de Giesen, N., Houser, P., Jaffe, P. R., Kollet, S., Lehner, B., Lettenmaier, D. P., Peters-Lidard, C., Sivapalan, M., Sheffield, J., Wade, A., and Whitehead, P.: Hyperresolution global land surface modeling: Meeting a grand challenge for monitoring Earth's terrestrial water, Water Resour. Res., 47, W05301, doi:10.1029/2010WR010090, 2011. 